\title{
The aerosol-climate model ECHAM5-HAM
}

\author{
P. Stier ${ }^{1}$, J. Feichter ${ }^{1}$, S. Kinne ${ }^{1}$, S. Kloster ${ }^{1}$, E. Vignati ${ }^{2}$, J. Wilson ${ }^{2}$, L. Ganzeveld ${ }^{3}$, I. Tegen ${ }^{4}$, M. Werner ${ }^{4}$,

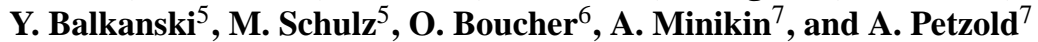 \\ ${ }^{1}$ Max Planck Institute for Meteorology, Hamburg, Germany \\ ${ }^{2}$ Institute for the Environment and Sustainability, European Commission Joint Research Centre, Ispra, Italy \\ ${ }^{3}$ Max Planck Institute for Chemistry, Mainz, Germany \\ ${ }^{4}$ Max Planck Institute for Biogeochemistry, Jena, Germany \\ ${ }^{5}$ Laboratoire des Sciences du Climat et de l'Environnement, Gif-sur-Yvette, France \\ ${ }^{6} \mathrm{CNRS}$, USTL, Villeneuve d'Ascq, France \\ ${ }^{7}$ German Aerospace Agency DLR, Oberpfaffenhofen, Germany
}

Received: 2 September 2004 - Published in Atmos. Chem. Phys. Discuss.: 22 September 2004

Revised: 4 March 2005 - Accepted: 15 March 2005 - Published: 31 March 2005

\begin{abstract}
The aerosol-climate modelling system ECHAM5HAM is introduced. It is based on a flexible microphysical approach and, as the number of externally imposed parameters is minimised, allows the application in a wide range of climate regimes. ECHAM5-HAM predicts the evolution of an ensemble of microphysically interacting internally- and externally-mixed aerosol populations as well as their sizedistribution and composition. The size-distribution is represented by a superposition of log-normal modes. In the current setup, the major global aerosol compounds sulfate (SU), black carbon (BC), particulate organic matter (POM), sea salt (SS), and mineral dust (DU) are included. The simulated global annual mean aerosol burdens (lifetimes) for the year 2000 are for SU: $0.80 \mathrm{Tg}(\mathrm{S})$ (3.9 days), for BC: 0.11 Tg (5.4 days), for POM: 0.99 Tg (5.4 days), for SS: 10.5 $\mathrm{Tg}$ (0.8 days), and for DU: $8.28 \mathrm{Tg}$ (4.6 days). An extensive evaluation with in-situ and remote sensing measurements underscores that the model results are generally in good agreement with observations of the global aerosol system. The simulated global annual mean aerosol optical depth (AOD) is with 0.14 in excellent agreement with an estimate derived from AERONET measurements (0.14) and a composite derived from MODIS-MISR satellite retrievals (0.16). Regionally, the deviations are not negligible. However, the main patterns of AOD attributable to anthropogenic activity are reproduced.
\end{abstract}

Correspondence to: P. Stier

(stier@dkrz.de)

\section{Introduction}

Atmospheric aerosols play an important role in the global climate system. Aerosol particles influence the global radiation budget directly, by scattering and absorption (Ångström, 1962; McCormic and Ludwig, 1967), as well as indirectly, by the modification of cloud properties (Twomey, 1974; Graß1, 1975; Twomey, 1977; Albrecht, 1989; Hansen et al., 1997; Lohmann, 2002), with feedbacks to the hydrological cycle (Lohmann and Feichter, 1997; Liepert et al., 2004). Furthermore, heterogeneous reactions on the aerosol surface and in liquid aerosol particles interact with the chemistry of the atmosphere (Ravishankara, 1997; Andreae and Crutzen, 1997; Crutzen, 1996; Dentener and Crutzen, 1993). Pollutants, such as DDT, condense on aerosol particles so that their transport and deposition are largely determined by the aerosol pathways (van Pul et al., 1998; Unsworth et al., 1999). Moreover, the deposition of aerosol in the ocean plays an important role in the biogeochemical cycle of the oceans (Vink and Measures, 2001; Johnson et al., 1997).

Nevertheless, the quantitative comprehension of the role of aerosols is still insufficient (e.g. Penner et al., 2001; Ramanathan et al., 2001; Heintzenberg et al., 2003).

To increase the understanding of this complex system, the ECHAM5 General Circulation Model (GCM) (Roeckner et al., 2003) has been extended by a complex aerosol model allowing long-term, i.e. depending on the model resolution centennial to millennial scale, transient climate simulations. A major objective is to quantify the aerosol radiative effects and their impacts on the global climate system for present day and future conditions.

(C) 2005 Author(s). This work is licensed under a Creative Commons License. 
Most previous studies of the global aerosol system (e.g. Langner and Rhode, 1991; Feichter et al., 1996; Roelofs et al., 1998; Lohmann et al., 1999a; Rasch et al., 2000; Chin et al., 2002) have simulated the global distribution of the mass of one or more of the major aerosol components: sulfate (SU), elemental carbon, henceforth denoted as black carbon (BC), particulate organic matter (POM), sea salt (SS), and mineral dust (DU). In these studies aerosol is either represented by an external mixture (e.g. Lohmann et al., 1999a; Tegen et al., 1997) or by an internal mixture with a fixed ratio of the individual components (e.g. Haywood et al., 1997b). An internal mixture refers to the assumption that all particles contain a uniform mixture of the individual components whilst an external mixture describes a mixture of particles each of which is made of solely one compound. However, observations show (e.g. Murphy et al., 1998; Bates et al., 1998; Seinfeld et al., 2004) that the mixing state of the global aerosol system is highly variable with a large internally mixed contribution and varying ratios among constituents. This important property of the global aerosol system can not be accounted for with the conventional bulk modelling approach, solely based on aerosol mass. Another drawback of the bulk modelling approach is that in order to calculate direct and indirect radiative effects, as well as the sinks of the aerosol mass itself, implicit assumptions about the aerosol size distribution have to be imposed. Many feedback cycles are highly sensitive to aerosol number and therefore to the size-distribution. In short, a comprehensive analysis of aerosol-climate interactions, including feedback processes, requires knowledge of the size-distribution, the composition, and the mixing state and therefore size-segregated, microphysical, multicomponent aerosol modules suitable for long-term integrations.

Tegen and Lacis (1997) simulated the size-distribution and radiative properties of mineral dust in a GCM with sizedependent sources and sinks without interaction among the size classes. Adams and Seinfeld (2002) predicted the sizedistribution of sulfate aerosol with an interactive approach. A number of studies, (e.g. Tegen et al., 1997; Jacobson, 2001; Takemura et al., 2000), incorporated partly size-segregated aerosol modules with several components into global aerosol models, neglecting the microphysical interaction among the components. Only recently, size-segregated, interactive multicomponent aerosol modules are embedded into global models allowing to simulate the mixing state explicitly. Wilson et al. (2001) represent the size-distribution in a multicomponent aerosol model by a superposition of eight partly interacting log-normal modes. Ghan et al. (2001a,b) use an interactive modal size-segregated multicomponent module to estimate the direct and indirect radiative aerosol forcing. Gong et al. (2003) describe the development of a size-segregated aerosol module and apply it to the simulation of the global sea-salt distribution (Gong et al., 2002). They have the option to treat fresh emissions as external mixture with a fixed aging time, assuming that the aging only occurs in the emis- sion grid box.

In the development of the ECHAM5-HAM aerosol model the attempt was made to minimise the number of externally imposed parameters. Aerosol size-distribution and composition are prognostic parameters. The modal setup allows to predict the evolution of an ensemble of interacting internallyand externally-mixed aerosol populations. The sink processes as well as the aerosol optical properties are calculated in dependence of size and composition. This setup allows the prediction of the aerosol radiative effects directly from the prognostic variables and provides the necessary parameters for the aerosol-cloud coupling. Computational efficiency of this aerosol model permits the application in long-term climate studies.

Section 2 describes the setup of the ECHAM5-HAM model. Results from a simulation for the year 2000 and their evaluation are presented in Sect. 3. Section 4 concludes the discussion and presents an outlook to future developments.

\section{Model description}

\subsection{The ECHAM5 general circulation model}

The atmospheric general circulation model ECHAM5 is the fifth-generation climate model developed at the Max Planck Institute for Meteorology, evolving from the model of the European Centre for Medium-Range Weather Forecasts (ECMWF). ECHAM5 solves prognostic equations for vorticity, divergence, surface pressure and temperature expressed in terms of spherical harmonics with a triangular truncation. Water vapour, cloud liquid water, cloud ice and trace components are transported with a flux form semiLagrangian transport scheme (Lin and Rood, 1996) on a Gaussian grid. ECHAM5 contains a new microphysical cloud scheme (Lohmann and Roeckner, 1996) with prognostic equations for cloud liquid water and ice. Cloud cover is predicted with a prognostic-statistical scheme solving equations for the distribution moments of total water (Tompkins, 2002). Convective clouds and convective transport are based on the mass-flux scheme of Tiedtke (1989) with modifications by Nordeng (1994). The solar radiation scheme (Fouquart and Bonnel, 1980) has 4 spectral bands, 1 for the visible and ultra-violet, and 3 for the near-infrared. The longwave radiation scheme (Mlawer et al., 1997; Morcrette et al., 1998) has 16 spectral bands. ECHAM5 has the capability to perform nudged simulations, i.e. to relax the prognostic variables towards an atmospheric reference state, such as forecast or re-analysis data from operational weather forecast models.

\subsection{The modal concept}

A fine discretisation of the wide aerosol spectrum is with current computational resources not efficient for the long term global prediction of interactive multicomponent aerosol distributions and their mixing state. Thus, the aerosol spectrum 
Table 1. The modal structure of HAM. $\mathrm{N}_{i}$ denotes the aerosol number of the mode $i$ and $\mathrm{M}_{i}^{j}$ denotes the mass of compound $j \in\{S U, B C, P O M, S S, D U\}$ in mode $i$. The ranges for $\bar{r}$ give the respective mode boundaries (see Section 2.7.7).

\begin{tabular}{lll}
\hline $\begin{array}{l}\text { Modes } \\
\bar{r}[\mu \mathrm{m}]\end{array}$ & Soluble / Mixed & Insoluble \\
\hline $\begin{array}{l}\text { Nucleation } \\
\bar{r} \leq 0.005\end{array}$ & $\mathrm{~N}_{1}, \mathrm{M}_{1}^{S U}$ & \\
$\begin{array}{l}\text { Aitken } \\
0.005<\bar{r} \leq 0.05\end{array}$ & $\mathrm{~N}_{2}, \mathrm{M}_{2}^{S U}, \mathrm{M}_{2}^{B C}, \mathrm{M}_{2}^{P O M}$ & \\
$\begin{array}{l}\text { Accumulation } \\
0.05<\bar{r} \leq 0.5\end{array}$ & $\mathrm{~N}_{3}, \mathrm{M}_{3}^{S U}, \mathrm{M}_{3}^{B C}, \mathrm{M}_{3}^{P O M}, \mathrm{M}_{3}^{S S}, \mathrm{M}_{3}^{D U}$ & $\mathrm{~N}_{6}, \mathrm{M}_{5}^{B C}, \mathrm{M}_{5}^{P U}$ \\
Coarse & $\mathrm{N}_{4}, \mathrm{M}_{4}^{S U}, \mathrm{M}_{4}^{B C}, \mathrm{M}_{4}^{P O M}, \mathrm{M}_{4}^{S S}, \mathrm{M}_{4}^{D U}$ & $\mathrm{~N}_{7}, \mathrm{M}_{7}^{D U}$ \\
$0.5<\bar{r}$ & & \\
\hline
\end{tabular}

in HAM is represented by the superposition of seven lognormal distributions:

$n(\ln r)=\sum_{i=1}^{7} \frac{N_{i}}{\sqrt{2 \pi} \ln \sigma_{i}} \exp \left(-\frac{\left(\ln r-\ln \bar{r}_{i}\right)^{2}}{2 \ln ^{2} \sigma_{i}}\right)$

Each mode $i$ of the aerosol number distribution can be described by the three moments aerosol number $N_{i}$, the number median radius $\overline{r_{i}}$, and the standard deviation $\sigma_{i}$. In HAM it is assumed that the standard deviation is constant and set to $\sigma=1.59$ for the nucleation, Aitken, and accumulation modes and to $\sigma=2.00$ for the coarse modes (Wilson et al., 2001). Thus, it is possible to calculate the median radius of each mode from the corresponding aerosol number and aerosol mass, which are transported as tracers. The modes of the aerosol model are composed either of compounds with no or low water-solubility, henceforth denoted as insoluble mode, or by an internal mixture of insoluble and soluble compounds, henceforth denoted as soluble mode.

The composition of each internally mixed mode can be modified by aerosol dynamics, e.g. coagulation, by thermodynamical processes, e.g. condensation of sulfate on preexisting particles, and by cloud processing. In this study we describe an implementation of the aerosol model with following components: sulfate, black carbon, organic matter, sea salt, and mineral dust. However, ECHAM5-HAM is flexible to be extended to more compounds. Table 1 illustrates the modal setup and the underlying mixing concept. The seven modes are grouped into four geometrical size classes, ranging from the nucleation, Aitken, and accumulation modes to the coarse mode size range. Each mode has a varying median radius and fixed mode boundaries used for the repartitioning between the modes as described in Sect. 2.7.7. Three of the modes are constituted solely of insoluble compounds, four of the modes contain at least one soluble compound. The modal setup is designed to allow an externally mixed contribution of initially insolubly emitted species.

\subsection{Emission module}

With the exception of the sulfur compounds, all emissions are treated as primary emissions, i.e. the compounds are assumed emitted as particulate matter. This is a realistic assumption for most of the treated species. However, it is only a proxy for the particulate fraction of organic matter. The prognostic treatment of the aerosol sizedistribution requires the knowledge of the emission sizedistribution. Additionally, the application of emissions in a GCM implies the assumption of homogeneous mixing across the model grid box with a typical scale of more than $100 \mathrm{~km}$. The emissions of dust, sea salt and oceanic dimethyl sulfide (DMS) are calculated online. Terrestrial biogenic DMS emissions are prescribed. For all other compounds, emission strength, distribution, and height are based on the AEROCOM (http://nansen.ipsl.jussieu.fr/AEROCOM/) emission inventory for the aerosol model inter-comparison experiment B (F. Dentener et al., in preparation ${ }^{1}$ ) representative for the year 2000. This emission inventory is henceforth denoted as ACB. The emission scenario is summarised in Table 2 and explained in more detail in the following paragraphs.

\subsubsection{Sulfur emissions}

We consider natural DMS emissions from the marine biosphere. The emission flux is calculated interactively from DMS seawater concentrations of Kettle and Andreae (2000) utilising the ECHAM5 $10 \mathrm{~m}$ wind speed to derive the airsea exchange rate following Nightingale et al. (2000). Terrestrial biogenic emissions in form of DMS are applied from Pham et al. (1995). Non-eruptive volcanic sulfur emissions are taken from Andres and Kasgnoc (1998) supplemented by eruptive emissions with locations following

\footnotetext{
${ }^{1}$ Emissions of primary aerosol and precursor gases in the years 2000 and 1750: a prescribed dataset for the AEROCOM experiment, Institute for the Environment and Sustainability, European Commission Joint Research Centre, Ispra, Italy.
} 


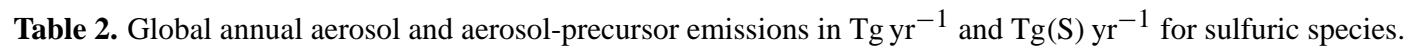

\begin{tabular}{|c|c|c|c|}
\hline Species & Source & Reference & $\mathrm{Tg} \mathrm{yr}^{-1}$ \\
\hline \multirow[t]{3}{*}{ DMS } & Marine Biosphere & Kettle and Andreae (2000) & 23.4 \\
\hline & & Nightingale et al. (2000) & \\
\hline & Terrestrial Biosphere & Pham et al. (1995) & 0.3 \\
\hline \multirow{4}{*}{$\mathbf{S O}_{2}$} & Volcanoes & Andres and Kasgnoc (1998) & 14.6 \\
\hline & & Halmer et al. (2002) & \\
\hline & Vegetation Fires & van der Werf et al. (2003) & 2.1 \\
\hline & $\begin{array}{l}\text { Industry, Fossil-Fuel, } \\
\text { Bio-Fuels }\end{array}$ & Cofala et al. (2005) & 54.2 \\
\hline Total sulfur & & & 94.6 \\
\hline \multirow[t]{3}{*}{ BC } & Vegetation Fires & van der Werf et al. (2003) & 3.0 \\
\hline & Fossil-Fuel & Bond et al. (2004) & 3.0 \\
\hline & Bio-Fuels & Bond et al. (2004) & 1.6 \\
\hline Total BC & & & 7.7 \\
\hline \multirow[t]{4}{*}{ POM } & Biogenic & Guenther et al. (1995) & 19.1 \\
\hline & Vegetation Fires & van der Werf et al. (2003) & 34.7 \\
\hline & Fossil-Fuel & Bond et al. (2004) & 3.4 \\
\hline & Bio-Fuels & Bond et al. (2004) & 9.1 \\
\hline Total POM & & & 66.3 \\
\hline SS & Wind driven & Schulz et al. (2004) & \\
\hline Accumulation & & & 54.3 \\
\hline Coarse & & & 4977.8 \\
\hline Total & & & 5032.1 \\
\hline DU & Wind driven & Tegen et al. (2002) & \\
\hline Accumulation & & & 7.5 \\
\hline Coarse & & & 654.9 \\
\hline Total & & & 662.4 \\
\hline alternative: & & Balkanski et al. (2004) & \\
\hline Total & & & 787.1 \\
\hline
\end{tabular}

Halmer et al. (2002) and a total strength recommended by GEIA (http://www.geiacenter.org). Non-eruptive emissions are distributed between the volcano height and one third below, eruptive emissions are distributed 500 to $1500 \mathrm{~m}$ above the volcano height (ACB). Anthropogenic sulfur emissions are considered from fossil-fuel and bio-fuel emissions (Cofala et al., 2005) and from vegetation fires (van der Werf et al., 2003). Emissions from industry, power-plants, and shipping are distributed between 100 and $300 \mathrm{~m}$ above surface (ACB). Vegetation fires inject emissions in heights well above the surface. We account for that, following ACB, by prescribing emission profiles derived from measured ecosystem specific injection heights (D. Lavoué, pers. comm.), ranging from 0 to $6 \mathrm{~km}$. Except for DMS, we assume $97.5 \%$ of all sulfuric emission in the form of $\mathrm{SO}_{2}$ and $2.5 \%$ in the form of primary sulfate (ACB). $50 \%$ of ship-, industrial-, and power-plant emissions are attributed to the accumulation mode with a number median radius $\bar{r}=0.075 \mu \mathrm{m}$ and $\sigma=1.59$ and $50 \%$ to the coarse mode with $\bar{r}=0.75 \mu \mathrm{m}$ and $\sigma=2.00$ (estimated from ACB recommendation of $\bar{r}=0.5 \mu \mathrm{m}$ and $\sigma=2.0$ ). Other primary sulfate emissions are attributed with $50 \%$ to the Aitken mode with $\bar{r}=0.03 \mu \mathrm{m}$ and $\sigma=1.59$ and with $50 \%$ to the accumulation mode with $\bar{r}=0.075$ and $\sigma=1.59$.

\subsubsection{Carbonaceous emissions}

Fossil-fuel and bio-fuel emissions for black and organic matter are used from Bond et al. (2004) assuming an emission size distribution with a number median radius of $\bar{r}=0.03 \mu \mathrm{m}$ and $\sigma=1.59$ (adapted to ECHAM5-HAM standard deviation from ACB recommendation $\bar{r}=0.015 \mu \mathrm{m}$ and $\sigma=1.8$ ). For carbonaceous emissions from vegetation fires (van der Werf et al., 2003) we assume $\bar{r}=0.075 \mu \mathrm{m}$ and $\sigma=1.59$ (adapted from ACB values $\bar{r}=0.04 \mu \mathrm{m}$ and $\sigma=1.8$ ) and injection heights as described in Section 2.3.1. The biogenic monoterpene emissions of Guenther et al. (1995), are scaled by the factor 0.15 to estimate the production of Secondary Organic Aerosol (SOA) from biogenic sources (ACB). Black carbon emissions are assumed insoluble. $65 \%$ of all POM emissions are assumed soluble (Mayol-Bracero et al., 2002) and emitted in the respective soluble mode, the insoluble fraction in the insoluble Aitken mode. The insoluble fraction of SOA is assumed to condense on the insoluble Aitken mode and the soluble fraction on the soluble Aitken and accumulation 
modes at the point of emission. For the conversion of the carbon mass of POM into the total mass of POM, a factor of 1.4 is applied (ACB). Considering the associated uncertainties and the simplified bulk treatment, hygroscopic growth of organic aerosols is currently neglected.

\subsubsection{Sea salt emissions}

Sea salt aerosol is produced by wind-induced formation of sea spray and its subsequent (partly) evaporation (e.g. Schulz et al., 2004). Numerous emission source functions have been developed, parameterising the emission flux as a function of the $10 \mathrm{~m}$ wind speed. Guelle et al. (2001) show that the emission source function can best be represented by a combination of the approach of Monahan et al. (1986) for the small particle range and of Smith and Harrison (1998) for the coarse particle range. Following their approach we merge the source functions smoothly in the size range $2-4 \mu \mathrm{m}$ dry radius and fit the combined source function by two lognormal distributions. The mass median radii as a function of wind speed decrease with increasing wind speed of 1 to $40 \mathrm{~m} \mathrm{~s}^{-1}$ from 0.284 to $0.271 \mu \mathrm{m}$ and from 2.25 to $2.15 \mu \mathrm{m}$ for the two modes, respectively (Schulz et al., 2004).

\subsubsection{Dust emissions}

For the emission of mineral dust, two optional schemes have been implemented into HAM: the scheme of Tegen et al. (2002) and the scheme of Balkanski et al. (2004). Both schemes are coupled online, i.e. they calculate the emission of mineral dust in dependence of the ECHAM5 wind speed and hydrological parameters. Freshly emitted dust is assumed insoluble. Tegen et al. (2002) derive preferential dust source areas from an explicit simulation of paleological lakes. In addition, lower dust emissions can occur in other non-vegetated regions. The emission flux is then calculated from 192 internal dust size-classes and the explicit formulation of the saltation process following Marticorena and Bergametti (1995). Balkanski et al. (2004) have associated threshold velocities derived by Marticorena and Bergametti (1995) to the mineralogical composition of the different soil types of the Food and Agriculture Organization of the United Nations (http://www.fao.org) over the same region. This allowed to extend the domain to obtain a global dust source formulation (Claquin, 1999). In addition, regional source strength were deduced for 12 arid regions by adjusting model optical depth to optical depth deduced from TOMS aerosol indices (Hsu et al., 1999).

For the implementation of the Tegen et al. (2002) scheme into ECHAM5-HAM, we fitted a multi-annual global mean of the emission size classes grouped into 24 bins with a superposition of three log-normal size-distributions. Considering the short life-time and the negligible contribution of the super-coarse mode to the radiative effect, we neglect the super-coarse mode emissions and apply the emission into the insoluble accumulation and coarse modes with massmedian radii of $0.37 \mu \mathrm{m}$ and $1.75 \mu \mathrm{m}$ and standard deviations of 1.59 and 2.00, respectively. For the Balkanski et al. (2004) scheme we also neglect the super-coarse mode emissions and emit into the insoluble coarse mode with a mass-median radius of $1.25 \mu \mathrm{m}$ and a standard deviation of 2.00.

A full description and comparison of the results of the two dust schemes is beyond the scope of this paper. Thus, unless otherwise quoted, we will focus henceforth on the results from the Tegen et al. (2002) scheme.

\subsection{Chemistry module}

The chemistry module is based on the sulfur cycle model as described by Feichter et al. (1996) treating the prognostic variables dimethyl sulfide (DMS), sulfur dioxide $\left(\mathrm{SO}_{2}\right)$ and sulfate $\left(\mathrm{SO}_{4}^{2-}\right)$. Three dimensional monthly mean oxidant fields of $\mathrm{OH}, \mathrm{H}_{2} \mathrm{O}_{2}, \mathrm{NO}_{2}$, and $\mathrm{O}_{3}$ are prescribed from calculations of the comprehensive MOZART chemical transport model (Horowitz et al., 2003). In the gas phase, DMS and $\mathrm{SO}_{2}$ are oxidised by hydroxyl $(\mathrm{OH})$ and DMS reacts with nitrate radicals $\left(\mathrm{NO}_{3}\right)$. In the aqueous phase the oxidation of $\mathrm{SO}_{2}$ by $\mathrm{H}_{2} \mathrm{O}_{2}$ and $\mathrm{O}_{3}$ are considered. The aqueous phase concentration of $\mathrm{SO}_{2}$ is calculated according to Henry's law, accounting for dissolution effects.

Gas-phase produced sulfate is attributed to the gaseous phase and allowed to condense on pre-existing particles or to nucleate by the aerosol microphysics module M7 (see Sect. 2.7.3). In the current model version, in-cloud produced sulfate is distributed to the available pre-existing accumulation mode and coarse mode aerosol particles according to the respective number concentrations. A more detailed treatment of in-cloud aerosol processing is subject of ongoing research activities and will be described in forthcoming publications. A more detailed treatment of in-cloud aerosol processing requires the introduction of cloud droplet and ice crystal numbers as prognostic parameters as well as size-resolved parameterizations for aerosol activation and aerosol-hydrometeor interactions. The introduction of these processes is subject of ongoing research activities and will be described in a forthcoming publication.

\subsection{Deposition module}

\subsubsection{Dry deposition}

The net surface fluxes, calculated by subtracting the dry deposition fluxes from the respective emission fluxes, provide the lower boundary conditions for the implicit vertical diffusion scheme of ECHAM5. The dry deposition flux is calculated as the product of the surface layer concentration and the dry deposition velocity:

$F_{d}=C \rho_{a i r} v_{d}$

where $C$ is the tracer mass or number mixing ratio, $\rho_{\text {air }}$ is the air density, and $v_{d}$ is the dry deposition velocity. The dry de- 
position velocities are calculated based on a serial resistance approach.

For gases, $v_{d}$ is calculated from the aerodynamic, quasilaminar boundary layer, and surface resistance according to the "big leaf" concept (Ganzeveld and Lelieveld, 1995; Ganzeveld et al., 1998) for the ECHAM5 fractional surface cover types (snow/ice, bare soil, vegetation, wet skin, water and sea ice) of each grid box. The surface resistances are generally prescribed except of some specific resistances, e.g. the $\mathrm{SO}_{2}$ soil resistance as a function of soil $\mathrm{pH}$, relative humidity, surface temperature, and the canopy resistance. The latter is calculated from ECHAM5's stomatal resistance and a monthly mean Leaf Area Index (LAI) inferred from a NDVI (Normalised Differential Vegetation Index) climatology (Gutman et al., 1995) and the Olson (1992) ecosystem database.

For aerosols we have implemented the dry deposition velocity model that has previously been applied to develop a sulfate aerosol dry deposition parameterisation (Ganzeveld et al., 1998). In contrast to using prescribed sulfate mass size distributions, which were used to develop the sulfate aerosol dry deposition parameterisation, we use in this study the explicitly calculated modal number and mass parameters to calculate the aerosol dry deposition velocity as a function of particle radius, density, turbulence, and surface cover properties. The dry deposition model calculates the bare soil and snow/ice aerosol dry deposition velocities according to Slinn (1976), over water according to Slinn and Slinn (1980), whereas the vegetation and wet skin aerosol dry deposition velocities are calculated according to Slinn (1982) and Gallagher et al. (2002). Over water, the effect of whitecaps in enhancing aerosol dry deposition according to Hummelshøj et al. (1992) is taken into account.

\subsubsection{Sedimentation}

Sedimentation of the aerosol particles is calculated throughout the atmospheric column. The calculation of the sedimentation velocity is based on the Stokes velocity

$v_{s}=\frac{2}{9} \frac{r^{2} \rho g C_{c}}{\mu}$

with the Cunningham slip-flow correction factor $C_{c}$ accounting for non-continuum effects (e.g. Seinfeld and Pandis, 1998):

$C_{c}=1+\frac{\lambda}{r}\left[1.257+0.4 \exp -\frac{1.1 r}{\lambda}\right]$

Here $v_{s}$ is the sedimentation velocity, $r$ the number or mass median radius, $\rho$ the particle density, $g$ the gravitational acceleration, $\mu$ the gas viscosity, and $\lambda$ the mean free path of air. To satisfy the Courant-Friedrich-Lewy stability criterion, the sedimentation velocity is limited to $v_{s}<\frac{\Delta z}{\Delta t}$ where $\Delta z$ is the layer thickness and $\Delta t$ is the model timestep.

\subsubsection{Wet deposition}

The fraction of scavenged tracers is calculated from the incloud content utilising the precipitation formation rate of the ECHAM5 cloud scheme. For gases, the partitioning between the air and the cloud water is calculated based on Henry's law (see e.g. Seinfeld and Pandis, 1998) whilst for aerosols it is prescribed in the form of a size- and composition-dependent scavenging parameter $R . R$ is defined as the fraction of the tracer in the cloudy part of the grid box that is embedded in the cloud liquid/ice water. Values of $R$ for stratiform clouds follow measurements of interstitial and in-cloud aerosol contents of Henning et al. (2004), with slight modifications, and for ice clouds are based on Feichter et al. (2004). It should be noted that for the accumulation and coarse mode $R$ is lower for mixed phase clouds than for liquid clouds due to the growth of ice crystals at the expense of water droplets as a result of the Bergeron-Findeisen process (Henning et al., 2004). For convective clouds, few size-resolved measurement data is available. Thus, assuming higher supersaturations and therefore activation into lower size-ranges, we increase $R$ in convective clouds for the soluble modes, which we assume to be potential cloud condensation nuclei. The prescribed values of $R$ are given in Table 3 .

For the scavenging by stratiform clouds, the local rate of change of tracer $i$ is calculated as:

$$
\frac{\Delta C_{i}}{\Delta t}=\frac{R_{i} C_{i} f^{c l}}{C_{\text {wat }}}\left(\frac{Q^{\text {liq }}}{f^{\text {liq }}}+\frac{Q^{i c e}}{f^{i c e}}\right)
$$

where $C_{i}, C_{\text {wat }}$ are mixing ratios of the tracer $i$ and total cloud water, respectively. $f^{c l}$ is the cloud fraction, $f^{l i q}$ and $f^{i c e}$ are the liquid- and ice fraction of the cloud water. $Q^{\text {liq }}$ and $Q^{i c e}$ are the respective sum of conversion rates of cloud liquid water and cloud ice to precipitation, via the processes auto-conversion, aggregation, and accretion.

Convective scavenging is coupled with the mass flux scheme of the convective tracer transport. In addition to the local change of the tracer tendency, the convective tracer fluxes have to be adjusted by the wet deposition. In convective updrafts the tracer mixing ratios are associated with the liquid- and ice-phase proportionally to the presence of the respective phase:

$C_{i}^{l i q}=C_{i} f^{l i q} \quad C_{i}^{i c e}=C_{i} f^{i c e}$

The change in tracer mixing ratio is calculated as

$\Delta C_{i}=\Delta C_{i}^{l i q}+\Delta C_{i}^{i c e}=C_{i}^{l i q} R_{i} E^{l i q}+C_{i}^{i c e} R_{i} E^{i c e}$

where $R_{i}$ is the scavenging parameter and $E^{l i q}$ and $E^{i c e}$ are the fractions of updraft liquid water and updraft ice water that are converted into precipitation during one timestep.

From the local $\Delta C_{i}$ for each layer $k$ the local grid-box mean deposition flux $\overline{F_{i}^{d e p}}$ and the grid-box mean tendency $\overline{\Delta C_{i}} / \Delta t$ are calculated:

$\overline{F_{i}^{d e p}}=\Delta C_{i} \overline{F^{u p}} \quad \frac{\overline{\Delta C_{i}}}{\Delta t}=\overline{F_{i}^{d e p}} \frac{g}{\Delta p}$ 
Table 3. Scavenging parameter $R$ for the modes of HAM

\begin{tabular}{lllll}
\hline Mode & $\begin{array}{l}\text { Stratiform } \\
\text { Liquid Clouds }\end{array}$ & $\begin{array}{l}\text { Stratiform } \\
\text { Mixed Clouds }\end{array}$ & $\begin{array}{l}\text { Stratiform } \\
\text { Ice clouds }\end{array}$ & $\begin{array}{l}\text { Convective } \\
\text { Mixed Clouds }\end{array}$ \\
\hline Nucleation Soluble & 0.10 & 0.10 & 0.10 & 0.20 \\
Aitken Soluble & 0.25 & 0.40 & 0.10 & 0.60 \\
Accumulation Soluble & 0.85 & 0.75 & 0.10 & 0.99 \\
Coarse Soluble & 0.99 & 0.75 & 0.10 & 0.99 \\
Aitken Insoluble & 0.20 & 0.10 & 0.10 & 0.20 \\
Accumulation Insoluble & 0.40 & 0.40 & 0.10 & 0.40 \\
Coarse Insoluble & 0.40 & 0.40 & 0.10 & 0.40 \\
\hline
\end{tabular}

Here $\overline{F^{u p}}$ is the grid-box mean updraft mass flux. The local deposition flux is integrated from the model top to the respective layer $k$ :

${\overline{F_{i}^{d e p}}}^{i n t}=\sum_{t o p}^{k} \overline{F_{i}^{d e p}}$

The mean updraft tracer flux $\overline{F_{i}^{u p}}$ for tracer $i$ is recalculated based on the updated updraft tracer mixing ratios:

$\overline{F_{i}^{u p}}=\left(C_{i}-\Delta C_{i}\right) \overline{F^{u p}}$

A non-negligible fraction of precipitation re-evaporates before it reaches the ground. Re-evaporation acts on the integrated tracer deposition flux ${\overline{F_{i}^{d e p}}}^{i n t}$ proportionally to the evaporation of precipitation:

$\Delta{\overline{F_{i}^{d e p}}}^{i n t}={\overline{F_{i}^{d e p}}}^{i n t} f^{\text {evap }}$

$\frac{\overline{\Delta C_{i}}}{\Delta t}=\Delta{\overline{F_{i}^{d e p}}}^{i n t} \frac{g}{\Delta p}$

where $f^{\text {evap }}$ is the evaporating fraction of precipitation, $\Delta p$ is the layer thickness in pressure units, and $g$ is the gravitational acceleration.

For aerosols, below-cloud scavenging is calculated from the ECHAM5 water- and ice- precipitation fluxes with prescribed size-dependent collection efficiencies $R_{i}^{r}$ and $R_{i}^{s}$ from Seinfeld and Pandis (1998) for rain and snow, normalised by the respective precipitation rate

$\frac{\overline{\Delta C_{i}}}{\Delta t}=C_{i}^{a m b} f^{\text {precip }}\left(R_{i}^{r} F^{r}+R_{i}^{s} F^{s}\right)$

where $C_{i}^{a m b}$ is the mass mixing ratio of the ambient cloud free air, $f^{\text {precip }}$ is the effective grid-box fraction affected by precipitation, and $F^{r}$ and $F^{s}$ are the fluxes of rain and snow, respectively. $f^{\text {precip }}$ is estimated in the stratiform scheme by the assumption of maximum overlap of the cloudy parts of the grid box and for the convective scheme from the estimated updraft area.

\subsection{Relative humidity}

Sub-grid scale variations in relative humidity can have a large impact on the water uptake of aerosols and their radiative forcing (e.g. Haywood et al., 1997a). As cloud processing of aerosols and cloud radiative effects predominate in the cloudy part of the grid box, it is desirable to apply ambient conditions for the aerosol microphysics and thermodynamics in the cloud free part. The usage of the grid mean relative humidity $\overline{R H}=\bar{q} / q^{s}$ leads to an overestimation of $R H$ in the cloud free part of a partly clouded grid box. The cause is that it can be assumed that air in the cloudy part of the grid box is close to saturation. Here $\bar{q}$ and $q^{s}$ are grid-mean and saturation specific humidities, respectively. This assumption allows to calculate the relative humidity in the cloud-free part of the grid box:

$R H^{a m b}=\frac{q^{a m b}}{q^{s}}$

where the ambient specific humidity $q^{a m b}$ is calculated from

$\bar{q}=q^{s} f^{c l}+q^{a m b}\left(1-f^{c l}\right)$

where $f^{c l}$ is the cloud fraction.

Turbulent sub-grid scale fluctuations of $R H$ are not accounted for in this study.

\subsection{The aerosol microphysics module M7}

The microphysical core of the ECHAM5-HAM aerosol model is the aerosol module M7 (Vignati et al., 2004) evolving from an earlier version M3+ that has already been used and tested in global aerosol modelling studies with offline chemical transport models (Wilson et al., 2001). M7 treats the aerosol dynamics and thermodynamics in the framework of the modal structure that is described in the Sect. 2.2. Only the major processes in M7 are described here as a thorough description and evaluation of M7 can be found in Vignati et al. (2004). 


\subsubsection{Coagulation}

The calculation of the coagulation coefficients is based on a parameterisation of the Brownian coagulation following Fuchs (1964). The coagulation coefficient for particles of modes $i$ and $j$ is:

$K_{i j}=\frac{16 \pi \tilde{r} \tilde{D}}{\frac{4 \tilde{D}}{\tilde{v} \tilde{r}}+\frac{\tilde{r}}{\tilde{r}+\tilde{\Delta}}}$

where $\tilde{D}, \tilde{v}$ and $\tilde{\Delta}$ are the diffusion coefficient, the thermal velocity and the mean free path length for particles with a mean radius of $\tilde{r}=\frac{\overline{r_{i}}+\overline{r_{j}}}{2}$, respectively.

\subsubsection{Condensation}

Under sulfate-limited conditions, the condensation on potentially pre-existing particles and the nucleation of new particles compete for the available gas phase sulfuric acid. The partitioning of sulfate between those processes is treated in M7 as follows:

In a first step, the total maximum amount of condensable sulfate on pre-existing particles is calculated. This process is limited by the availability of gas phase sulfate and the diffusion of the sulfate to the surface of the particles. The calculation follows the methodology of Fuchs (1959) matching the diffusion in the kinetic and continuous regimes. The distinction between condensation on insoluble and on mixed/insoluble particles is realized by the assumption of different accommodation coefficients of $\alpha=0.3$ for the insoluble and $\alpha=1.0$ for the soluble particles (see Vignati et al., 2004).

In the second step, the remaining gas phase sulfate is available for the nucleation of new clusters.

\subsubsection{Nucleation}

The calculation of the number of nucleated particles is based on the classical nucleation theory in the binary sulfate/water system accounting for the effects of hydratisation. From the parameters temperature $(T)$, relative humidity $(R H)$, as well as the gas-phase concentration of the sulfate available after the condensation (see 2.7.2) the number of nucleated particles as well as the integral mass of the nucleated sulfate is parameterised following Vehkamäki et al. (2002). Compared to the earlier tested and optionally available scheme by Kulmala et al. (1998) this scheme has the advantage of an extended range of thermodynamical conditions $(0.01 \%<R H<100 \%$, $230.15 \mathrm{~K}<T<305.15 \mathrm{~K}$ ) and the usage of a more stringent application of nucleation theory. The predicted nucleation rate is then integrated analytically to calculate the number of nucleated particles over one timestep. The corresponding nucleated mass of sulfate is then derived based on the predicted nucleation cluster size starting at four molecules.

\subsubsection{Thermodynamics}

For particles containing sulfate, the calculation of the thermodynamical equilibrium with the water vapour phase is based on a generalised form of the Kelvin equation. For computational efficiency the parameterisation is realized in form of a look-up table. The calculation of the water content of particles that contain beside sulfate insoluble components, such as dust or black carbon, is done analogous to pure sulfate particles but with the dry radii of the total compounds.

With increasing ambient relative humidity, when the humidity reaches the Deliquescence Relative Humidity $(D R H)$, particles containing sea salt grow spontaneously by water uptake from the surrounding air. With decreasing ambient humidity, the sea salt aerosol releases the up-taken water not until a relative humidity well below the $D R H$, the so called Efflorescence Relative Humidity $(E R H)$. This hysteresis phenomenon is not taken into account in the current version of M7. In fact, as sea-salt aerosol is formed from the evaporation of larger droplets, it is assumed that particles do not release their water down to $E R H=45 \%$ (from Tang (1997)). The aerosol water content of particles containing sea salt in conditions of $R H>E R H$ is calculated as follows.

$W=\sum_{i} \frac{c_{i}}{m_{i}}$

Here are $W$ the aerosol water content $\left[\mathrm{g} \mathrm{m}^{-3}\right], c_{i}$ concentration of compound $i\left[\mathrm{~mol} \mathrm{~m}^{-3}\right]$ and $m_{i}$ the binary molality of compound $i\left[\mathrm{~mol} \mathrm{~g}^{-1}\right]$. It is assumed, based on the ZSRRelation (Zadanovskii, 1948; Stokes and Robinson, 1966), that the water activity of mixtures of electrolytes is equal to the water activity of the binary electrolyte-water mixture. The calculation of the binary molalities is done as follows

$m_{i}=\left(\sum_{j=0}^{7} Y_{j}(R H)^{j}\right)^{2}$

where $R H$ is the relative humidity (water activity) and $Y_{j}$ are empirical coefficients from Jacobson et al. (1996).

\subsubsection{Integration of the aerosol dynamics equation}

Analytical solutions are applied to integrate the aerosol dynamics equation for each mode, calculating the updated aerosol numbers and the transfer between the modes.

The aerosol dynamics equation for the soluble modes $(1 \leq i \leq n s)$ can be expressed as:

$$
\begin{aligned}
\frac{d N_{i}}{d t}= & -\frac{1}{2} K_{i i} N_{i}^{2} \\
& -N_{i}\left[\sum_{j=i+1}^{n s} K_{i j} N_{j}+\sum_{j=i+n s}^{n s+n i} K_{i j} N_{j}\right]+\delta_{i 1} c
\end{aligned}
$$

The first term on the right hand side represents the intramodal coagulation, the second term the inter-modal coagulation and the third term the nucleation. Here $N_{i}$ is the particle 
number, $K_{i j}$ the coagulation coefficient for the coagulation of mode $i$ and mode $j$, and $\mathrm{c}$ the nucleation rate. The intermodal coagulation consists of a contribution of coagulation with larger soluble modes as well as a contribution of coagulation with particles of larger insoluble modes.

For the insoluble modes, the coagulation also with smaller soluble particles is a sink as in this case the particles are transferred to the soluble/mixed mode. The coagulation with higher insoluble modes however, is considered inefficient for the insoluble modes. Therefore, the aerosol dynamics equation for the insoluble modes $(n s+1 \leq i \leq n s+n i)$ can be expressed as

$\frac{d N_{i}}{d t}=-\frac{1}{2} K_{i i} N_{i}^{2}-N_{i}\left[\sum_{j=1}^{n s} K_{i j} N_{j}\right]$

For the insoluble dust modes, the first term on the right hand side, representing the intra-modal coagulation, is negligible and thus omitted. The second term of the right hand side, accounting for the inter-modal coagulation with soluble modes, is treated operator split in a subsequent procedure (see Sects. 2.7.6 and Vignati et al. (2004) for more details).

From the analytically integrated changes in the aerosol numbers, the corresponding aerosol mass concentrations are then calculated mass conserving by summing up the number of particles transferred between the modes and multiplication with the respective mean particle masses.

\subsubsection{Transfer from the insoluble- to the mixed-modes}

Particles in the insoluble modes are transformed to the corresponding soluble/mixed mode by condensation of sulfate on their surface or by coagulation with particles of soluble modes. The total condensable sulfate on the respective mode (see 2.7.2) and the sulfate added to this mode by coagulation are attributed to the number of particles that can be coated with a minimal layer of sulfate. We assume a mono-layer for this minimal layer thickness (see Vignati et al., 2004). Particle numbers and masses of the coated particles, as well as the sulfate mass available through condensation and coagulation, are then transferred to the corresponding soluble mode.

\subsubsection{Repartitioning between the modes}

The previously described processes would cause a significant overlap between the modes. For example, nucleation mode particles typically grow by coagulation and condensation via the Aitken mode into the accumulation mode. Numerically, this leads to the fact that the mode median radius, but also the mode standard deviation, would increase steadily, associated with numerical diffusion. A mode merging algorithm (Vignati et al., 2004) is applied to repartition the particles among the modes and to confine the number median radius of each mode to the range given in Table 1.
Table 4. Complex refractive index by component at $\lambda=550 \mathrm{~nm}$.

\begin{tabular}{lll}
\hline Species & Refractive Index & Reference \\
\hline SU & $1.43+1.0 \times 10^{-8} i$ & Hess et al. (1998) \\
BC & $1.75+4.4 \times 10^{-1} i$ & Hess et al. (1998) \\
POM & $1.53+5.5 \times 10^{-3} i$ & Koepke et al. (1997) \\
SS & $1.49+1.0 \times 10^{-6} i$ & Shettle and Fenn (1979) \\
DU & $1.52+1.1 \times 10^{-3} i$ & Kinne et al. (2003) \\
WAT & $1.33+2.0 \times 10^{-7} i$ & Downing and Williams (1975) \\
\hline
\end{tabular}

\subsection{Radiation module}

The prognostic treatment of size-distribution, composition, and mixing state allows the explicit calculation of the aerosol optical properties in the framework of the Mie theory. However, the online calculation of the aerosol optical properties is computationally expensive. Therefore, the required aerosol optical properties are pre-computed from Mie theory for 24 solar spectral bands, following Toon and Ackerman (1981), and supplied in look-up tables with the three dimensions: Mie size-parameter $(X=2 \pi r / \lambda)$, and real- and imaginary part $\left(n_{r}\right.$ and $\left.n_{i}\right)$ of the refractive index. Here $r$ is the number median radius of the log-normal mode and $\lambda$ is the wavelength. The geometric arrangement of internally mixed components can be complex. Without prior knowledge we approximate $\left(n_{r}\right)$ and $\left(n_{i}\right)$ for each mode by a volume weighted average of the refractive indices of the components, including the diagnosed aerosol water (WAT) (see 2.7.4). The error of this approximation on $n_{r}$ is typically negligible and can reach $\approx 15 \%$ for $n_{i}$ for the extreme case of a mixture of BC and WAT (Lesins et al., 2002). Table 4 lists the used refractive indices for the components at $\lambda=550 \mathrm{~nm}$. Note that for dust the derivation of $n_{i}$ from AERONET measurements (Kinne et al., 2003) results in a significantly reduced absorption compared to earlier estimates (e.g. Moulin et al. (1997): $n_{i}=1.0 \times 10^{-2} i$ at $\lambda=550 \mathrm{~nm}$ ) and used in most previous studies (e.g. Schulz et al., 1998; Chin et al., 2002).

The table lookup procedure provides extinction cross section, single scattering albedo, and assymetry factor for each mode. The values from the 24 solar spectral bands are mapped to the 4 solar ECHAM5 bands, weighted with bottom of the atmosphere clear-sky solar fluxes. The parameters for the seven aerosol modes are combined to provide the necessary input to the ECHAM5 radiation scheme. In this study, only the effect of aerosols on the solar part of the spectrum is considered.

\section{Results and evaluation}

The simulations are performed for the year 2000 after a spin-up period of four months. ECHAM5 is nudged to the ECMWF ERA40 reanalysis data (Simmons and Gibson, 
Table 5. Global annual mean sources, burden, lifetime and sinks of aerosols and their precursors. Mass units of sulfuric species are in $\mathrm{Tg}(\mathrm{S})$.

\begin{tabular}{lrrrrrrrrr}
\hline Species & $\begin{array}{r}\text { Total } \\
\text { Sources } \\
{\left[\mathrm{Tg} \mathrm{yr}^{-1}\right]}\end{array}$ & Burden & Lifetime & $\begin{array}{r}\text { Wet } \\
\text { Deposition } \\
{[\%]}\end{array}$ & $\begin{array}{r}\text { Dry } \\
\text { Deposition } \\
{[\%]}\end{array}$ & Sedimentation & Chemistry & Condensation & Nucleation \\
& $7 \%]$ & {$[\%]$} & {$[\%]$} & {$[\%]$} \\
\hline $\mathrm{SU}$ & 76.1 & 0.80 & 3.9 & 95.1 & 2.8 & 2.1 & & & \\
$\mathrm{BC}$ & 7.7 & 0.11 & 5.4 & 92.2 & 7.5 & 0.3 & & & \\
$\mathrm{POM}$ & 66.1 & 0.99 & 5.4 & 92.4 & 7.3 & 0.3 & & & \\
$\mathrm{SS}$ & 5032.2 & 10.50 & 0.8 & 53.8 & 18.7 & 27.5 & & \\
$\mathrm{DU}$ & 662.4 & 8.28 & 4.6 & 55.3 & 5.5 & 39.2 & & & \\
$\mathrm{SO}_{2}$ & 92.0 & 0.67 & 2.7 & 4.2 & 16.3 & & 79.5 & \\
$\mathrm{SU}_{\text {gas }}$ & 28.0 & 0.00088 & 0.01 & 0.2 & 0.0 & & & \\
$\mathrm{DMS}$ & 23.4 & 0.077 & 1.2 & & & & 100.0 & & \\
\hline
\end{tabular}

2000). Horizontally, the resolution is T63 in spectral space with a corresponding resolution of $1.8^{\circ} \times 1.8^{\circ}$ on a Gaussian grid. The vertical resolution is set to 31 levels, extending from the surface up to $10 \mathrm{hPa}$. The prescribed emissions have the base year 2000.

Up to date, only limited measurement datasets of the global aerosol distribution are available. In situ measurements, in particular from aircraft campaigns, provide valuable reference cases for the model performance. However, their limited temporal and spatial extent complicate a comparison with global aerosol model simulations. Satellite measurements are currently still limited to integral properties, such as aerosol optical depth (AOD) and the Ångström parameter. The absence of continuous global measurements with a vertical extent render a full validation of the simulated global mean aerosol distribution impossible. Nevertheless, the attempt is made to evaluate the simulations by comparing a wide range of simulated parameters with available measurements.

\subsection{Emissions}

Annual mean emission distribution by species and global annual totals are depicted in Fig. 1. The partitioning by source type is given in Table 2. Emissions of the sulfuric compounds sulfur dioxide, sulfate, and DMS are displayed in terms of emissions of sulfur. The local maxima of sulfuric emissions can be attributed to anthropogenic emissions in the northern hemisphere. However, in the global mean, $40.9 \%$ of total sulfuric emissions have a natural origin with $24.6 \%$ from the marine biosphere, $15.3 \%$ from volcanoes, and $0.95 \%$ from the terrestrial biosphere. Vegetation fire emissions are considered here as anthropogenic. The regions of highest sea salt emissions coincide with the oceanic storm-track regions. The dominant contribution to the $\mathrm{BC}$ emissions is from fossiland bio-fuel usage with $61.0 \%$, supplemented by vegetation fires with $39.0 \%$. Vegetation fires dominate the POM emissions with a contribution of $52.3 \%$ followed by biogenic and fossil- and bio-fuel emissions with $28.8 \%$ and $18.9 \%$, re- spectively. For mineral dust, results from the Tegen et al. (2002) and Balkanski et al. (2004) schemes are displayed. Both schemes show a region of intense dust emissions over North Africa and agree in the large scale emission patterns. However, the Balkanski et al. (2004) emissions are generally patchier. Regionally the differences are not negligible. The Balkanski et al. (2004) scheme produces a distinct maximum of dust emissions in the region of the Thar desert in North-West India and the Tegen et al. (2002) scheme higher emissions in the Caspian Sea region, eastern Asia, western South-America, and Australia.

\subsection{Budgets and lifetime}

The components of the simulated ensemble of multiple internally-mixed aerosol modes are not independent as in classical bulk aerosol models, since microphysical processes affect the components of each internally mixed mode likewise. However, the summation of the budgets of the components over all modes gives insight in their cycling and facilitates the comparison with results from other studies. Annual mean total sources, column burden, lifetime, and sink processes as sum for each aerosol compound and precursors are listed in Table 5. Hereby, the lifetime is estimated as the ratio of the column burden to the total sources. The sulfate burden lies with $0.80 \mathrm{Tg}$ in the range of previous estimates (Langner and Rhode (1991): $0.77 \mathrm{Tg}$; Feichter et al. (1996): $0.57 \mathrm{Tg}$; Chin et al. (1996): 0.53 Tg; Roelofs et al. (1998): $0.96 \mathrm{Tg}$, Lohmann et al. (1999b): 1.03, Rasch et al. (2000): 0.60 Tg), as lies the lifetime with 3.9 days (Langner and Rhode (1991): 5.3 days; Feichter et al. (1996): 4.3 days; Chin et al. (1996): 3.9 days). As shown in Ganzeveld et al. (1998), the usage of their serial resistance dry deposition scheme results in significantly lower $\mathrm{SO}_{2}$ dry deposition (here $16.3 \%$ of total sink) than in many previous studies. This yields a relatively high burden of $\mathrm{SO}_{2}$ of $0.67 \mathrm{Tg}$, contributes to the relatively high burden of sulfate, and leaves the chemical conversion with $79.5 \%$ as the dominating sink for $\mathrm{SO}_{2}$. Of the gas-phase produced sulfuric acid, $99.4 \%$ condenses on pre- 
(a)

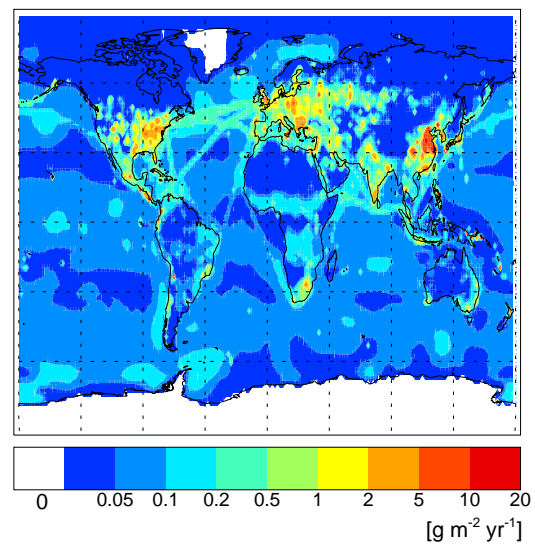

(c)

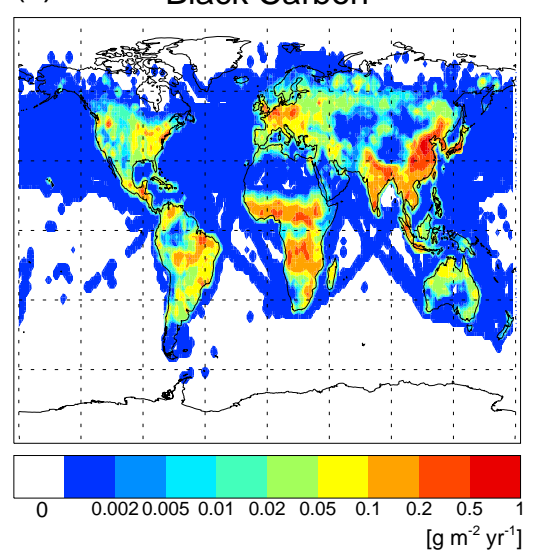

(e) Dust (Tegen et al., 2002)

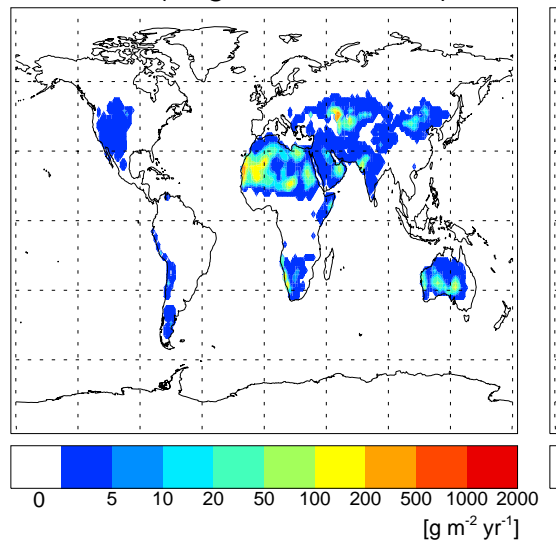

(b)

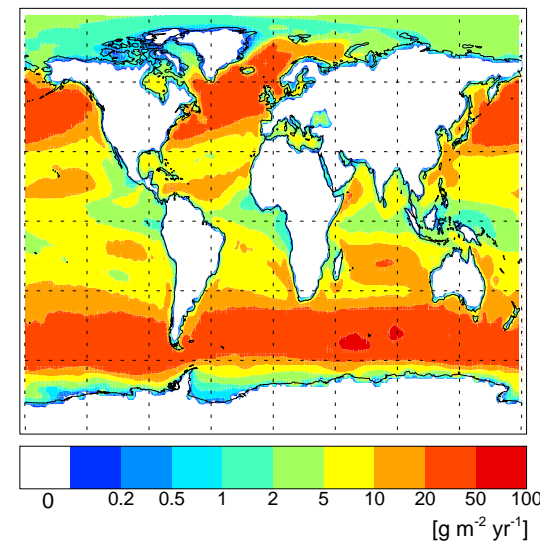

(d) Particulate Organic Matter

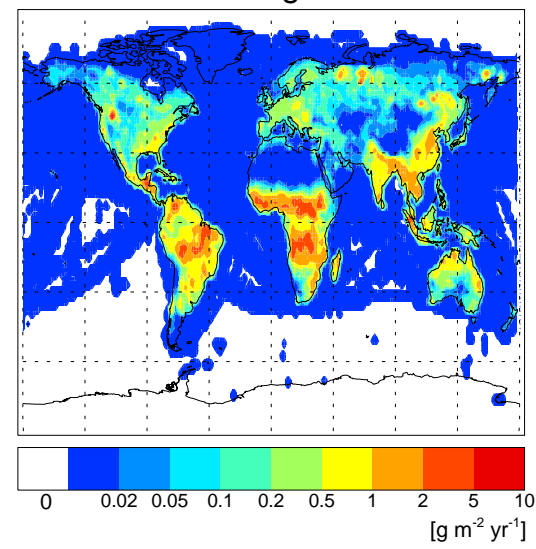

(f) Dust (Balkanski et al., 2004)

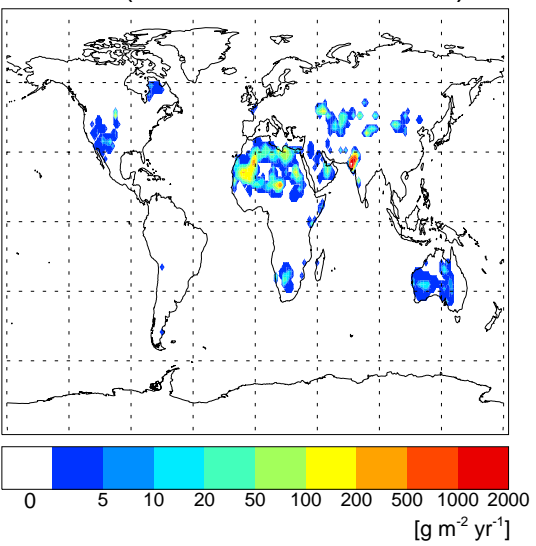

Fig. 1. Annual mean emission distribution by species. For dust emissions results of the Tegen et al. (2002) scheme and of the Balkanski et al. (2004) scheme are displayed.

existing aerosol, $0.4 \%$ nucleates and $0.2 \%$ is wet deposited. The DMS burden lies with $0.077 \mathrm{Tg}$ in the range of previous estimates (Feichter et al. (1996): 0.102 Tg; Chin et al. (1996): $0.059 \mathrm{Tg}$ ). For BC and POM the simulated burdens of $0.11 \mathrm{Tg}$ and $0.99 \mathrm{Tg}$, respectively, are lower than previous estimates, e.g. Lohmann et al. (1999a): 0.26 Tg, Wilson et al. (2001): $0.22 \mathrm{Tg}$, Chung and Seinfeld (2002): $0.22 \mathrm{Tg}$ for BC, and e.g. Lohmann et al. (1999a): $1.87 \mathrm{Tg}$, Chung and Seinfeld (2002): $1.39 \mathrm{Tg}$ for POM, respectively. This is consistent with the lower emissions of $\mathrm{BC}$ of $7.7 \mathrm{Tg}$ compared to $11.7 \mathrm{Tg}$ in e.g. Lohmann et al. (1999a) and of POM of 66.1 Tg compared to $105 \mathrm{Tg}$ in Lohmann et al. (1999a). The 
(a)

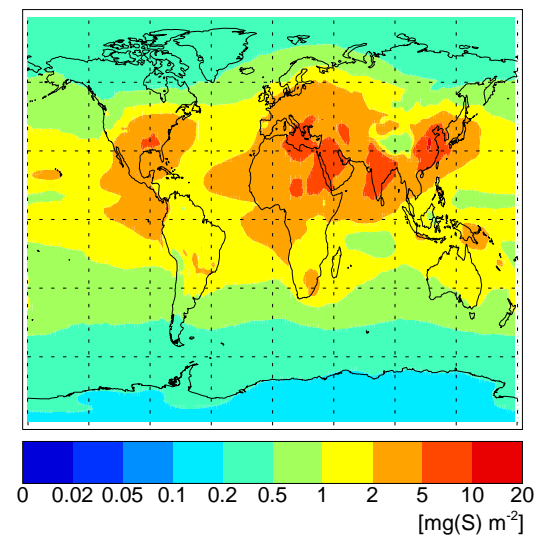

(c)

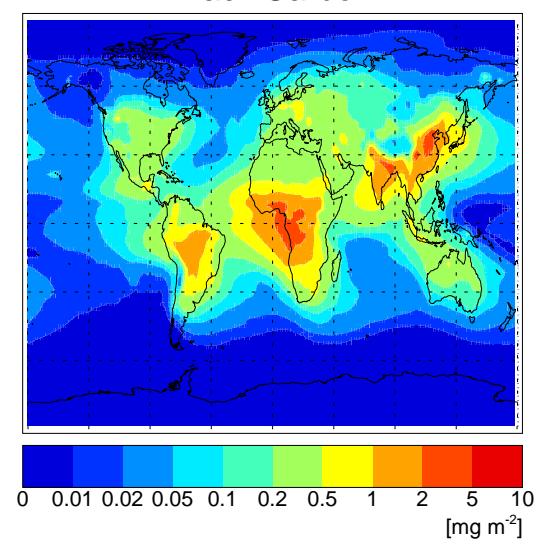

(e)

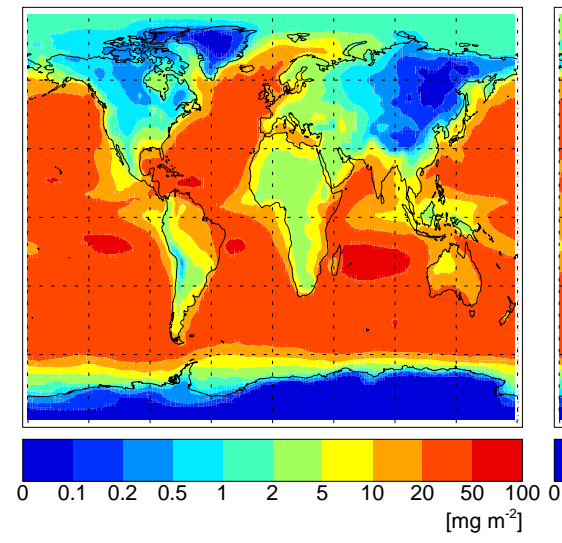

(b) Dust

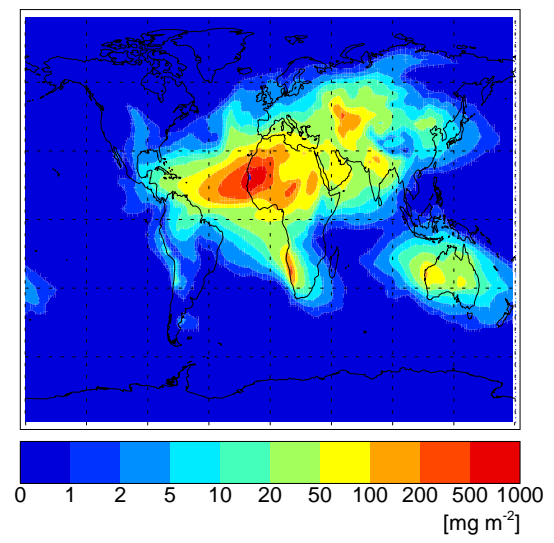

(d) Particulate Organic Matter

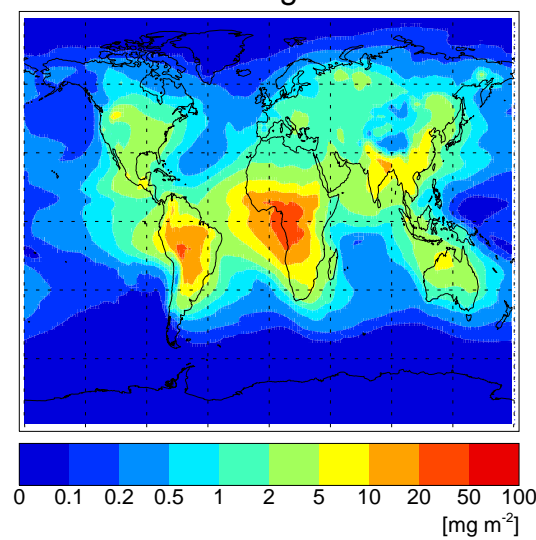

(f)

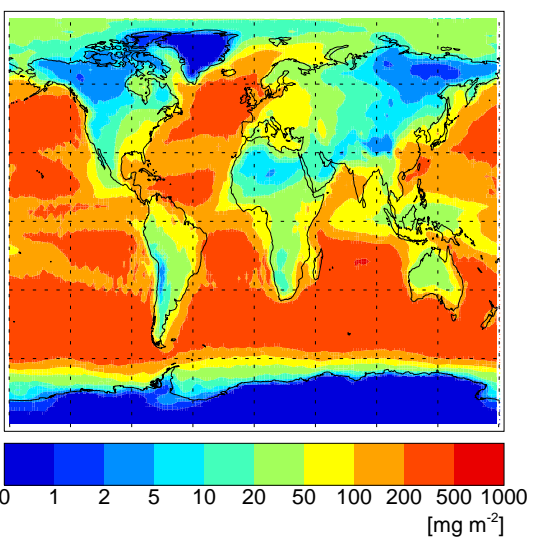

Fig. 2. Annual mean vertically integrated column mass. The mass of sulfate is given in terms of sulfur mass.

BC and POM lifetimes are with 5.4 days comparable with previous estimates (e.g. Lohmann et al., 1999a): 6.8 days for BC and 5.1 days for POM). For sea salt, with a burden of $10.5 \mathrm{Tg}$, a comparison with other studies is prevented by the fact that the emitted mass strongly depends on the assumed upper cut-off of the emissions size distribution. Due to its size and solubility, sea salt has the shortest lifetime with 0.8 days. The simulated dust burden is $8.28 \mathrm{Tg}$. The neglect of the super-coarse mode dust aerosol impedes the comparison of the budgets to other studies and results in a relatively long lifetime of 4.6 days. Wet deposition accounts to $55.3 \%$ of the total sink, dry deposition to $5.5 \%$, and sedimentation to $39.2 \%$. 

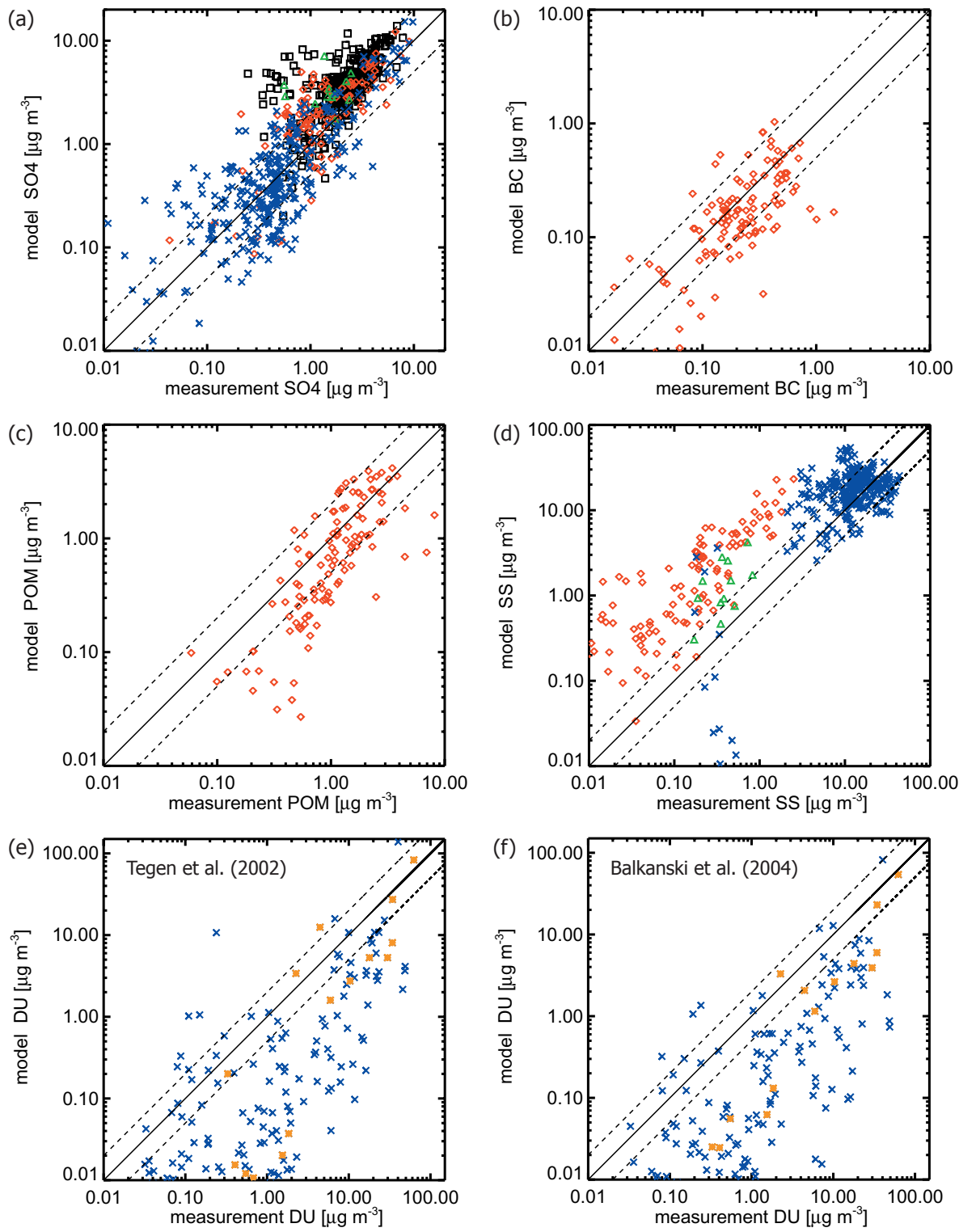

Fig. 3. Scatter plot of simulated and measured monthly mean surface aerosol mass concentrations of (a) sulfate, (b) black carbon, (c) particulate organic matter, (d) sea salt, (e) dust (Tegen et al., 2002), and (f) dust (Balkanski et al., 2004). Units of sulfate are $\mu \mathrm{g}\left(\mathrm{SO}_{4}\right) \mathrm{m}^{-3}$ and for the other compounds $\mu \mathrm{g} \mathrm{m}^{-3}$. EMEP measurements in black, IMPROVE in red, University of Miami in blue, and GAW in green. For dust, the month with the observed peak concentration is highlighted in orange. The solid line indicates the 1:1 ratio, the dashed lines the $2: 1$ and $1: 2$ ratios.

Microphysical aging, i.e. coagulation with soluble particles and sulfate coating, transfers particles from the insoluble to the soluble modes. For the initially insoluble BC, $89 \%$ of the mass is transfered to the soluble modes before removal, with a corresponding aging time of 0.7 days. This is faster than the pure condensational aging of pure $\mathrm{BC}$ with 1.4 days in Wilson et al. (2001). For the insoluble fraction of POM, for which a large fraction is emitted from biogenic sources in unpolluted areas, the aging is somewhat slower so that $86 \%$ are aged, with an aging time of 1.1 days. With 4.8 days the aging time for the larger dust particles is longer, however, still $46 \%$ are transfered to the soluble modes, with a subsequent increase of the scavenging efficiency, before removal.

\subsection{Mass distribution}

As for budgets and lifetime, the mass distributions of the internally-mixed components are coherent. Figure 2 shows the annual mean vertically integrated aerosol mass (burden) for each component as sum over the modes. The maxima 
of the sulfate burden lie close to the sources of sulfate and its precursors in the polluted regions of the northern hemisphere. However, substantial export of sulfate occurs to low emission regions such as the Middle East and northern Africa, the North Atlantic, and the North Pacific. The pronounced export to the Middle East and northern Africa seems facilitated by the usage of the interactive dry deposition scheme. As described in Ganzeveld et al. (1998), it calculates lower dry deposition velocities for $\mathrm{SO}_{2}$ in that region than prescribed in many other studies, resulting in higher sulfate precursor concentrations. Additionally, the consideration of low roughness velocities over bare soils also results in low aerosol dry deposition, which is a major sink in that region, characterised by low precipitation. The burden of dust shows a distinct maximum extending from the north-western African source regions into the Atlantic. The distribution of the carbonaceous compounds BC and POM resembles the emission distribution. Despite the dominant contribution of the storm tracks to the total sea salt emissions, sea salt burdens are also high over secondary source regions. The reason is that the storm tracks coincide with the strongest sink regions due to the associated precipitation. Therefore, regions such as the subtropical bands show, despite lower emissions, considerable column burdens of sea salt. Also shown is the burden of the total diagnosed aerosol water. From comparison with the distribution of the other compounds, it becomes evident that the dominant fraction of aerosol water is associated with sea salt. However, over regions with high sulfate burden the uptake by sulfate is discernible.

To evaluate the simulated mass distributions, we compare the modelled aerosol mass concentration of the lowest model level with surface measurements for the year 2000 from the European EMEP (http://www.emep.int) and North-American IMPROVE (http://vista.cira.colostate.edu/ improve/) measurement networks as well as to measurements compiled by the Global Atmosphere Watch (GAW) program (http://ies.jrc.cec.eu.int/wdca/). As most of these stations are at continental sites, we also include the comparison with a climatological compilation of multi-annual measurements at remote marine sites by courtesy of J. Prospero and D. Savoie (University of Miami), henceforth denoted as University of Miami compilation.

To ensure comparability, stations deviating in height by more than $200 \mathrm{~m}$ from the lowest model level are rejected. For the year 2000 measurements from the EMEP, IMPROVE, and GAW networks, we sample the daily mean model output with the measurement occurrences, i.e. we include only days with measurements in the derivation of the model monthly mean values. Monthly means derived from less than 6 measurements are rejected. For the University of Miami dataset no information on the measurement dates and number of measurements is available. Thus we use the whole model monthly mean for the comparison. A list of the measurement locations, with corresponding model and measurement annual mean and standard deviation, and the total number of measurements can be found in Appendix A. Figure 3 shows scatterplots for the observed and simulated monthly mean surface mass concentrations for the different networks.

The comparison of SU with the North-American IMPROVE measurement sites shows a good agreement with a slight tendency to overestimate. Out of a total of 112 samples, $74(66 \%)$ agree within a factor of 2 with the measurements. In comparison with the EMEP stations, distributed over Europe, the overestimation is more pronounced. However, still $182(64 \%)$ out of 283 samples lie within a factor of 2. SU mass concentrations agree well with the GAW (7 (58\%) out of 12) and University of Miami compilations (196 (58\%) out of 336).

For BC, measurements are only available from the North American IMPROVE network. The simulated surface BC masses show a good agreement with the measurements. Out of a total of 115 samples, 75 (65\%) agree within a factor of 2. Considering the uncertainties associated with the SOA formation, the agreement for POM with 62 out of 115 samples $(54 \%)$ within a factor of 2 , is remarkable.

SS mass concentrations compare well with the remote marine measurements of the University of Miami dataset (181 (63\%) out of 288 samples lie within a factor of 2 with the measurements) with a slight positive bias. Three measurement sites with exceptionally high SS concentrations have been rejected as they are likely contaminated by local surf (D. Savoie, pers. comm.). For the predominantly continental measurement sites from the IMPROVE and GAW networks, the low SS concentrations are substantially overestimated by the model, so that only 5 samples $(4 \%)$ out of 113 for IMPROVE and 3 samples (25\%) out of 12 for GAW agree within a factor of 2 with the measurements. This overestimation can possibly be attributed to numerical diffusion associated with the strong gradients of sea salt along the coast lines.

For the seasonal and inter-annual highly variable dust cycle, the comparison with the climatological University of Miami data set shows a large scatter and low agreement for both, the Tegen et al. (2002) and the Balkanski et al. (2004) emission schemes. Generally, the predicted mass concentrations are underestimated, a fact that is particularly pronounced for low dust concentrations. Out of 244 measurements, only 24 (10\%) (Tegen et al., 2002) and $15(6 \%)$ (Balkanski et al., 2004) lie within a factor of 2 of the measurements. The better agreement of the annual peak concentrations for each station, highlighted in orange, indicates that the distinct dust events are better captured than the lower background concentrations responsible for a large part of the scatter. It has to be stressed that in a comparison of a one year simulation with a climatological dataset a not too good agreement can be expected. Further, as shown by Timmreck and Schulz (2004) based on a study with the ECHAM4 GCM and the Balkanski et al. (2004) emission scheme, the application of the nudging technique influences the wind statistics and spatial distribution, 

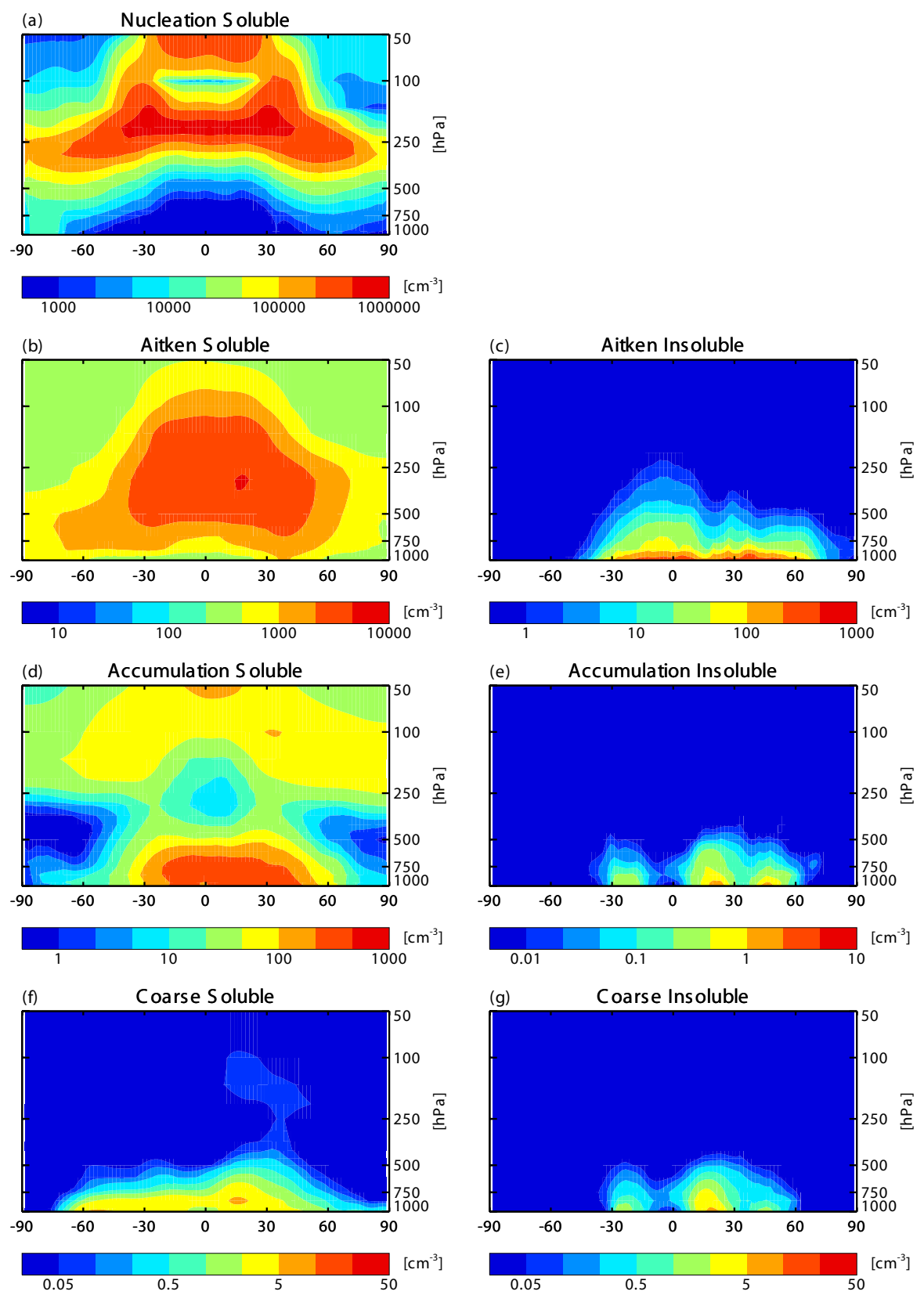

Fig. 4. Annual-mean zonal-mean number concentration for each mode [ $\left.\mathrm{cm}^{-3} \mathrm{STP}(1013.25 \mathrm{hPa}, 273.15 \mathrm{~K})\right]$.

substantially reducing the dust emissions. Other potential explanations include: the neglect of the super-coarse mode emissions, a too low emission strength particularly of the Asian dust sources dominating a large part of the Pacific measurement sites, an overestimation of sink processes, possibly due to too efficient microphysical aging, as well as the influence of non-represented local sources on the dust measurements.

\subsection{Number distribution}

The annual-mean zonal-mean aerosol number concentration (N) for the seven modes is shown in Fig. 4. Nucleation is favoured in regions with little available aerosol surface area, low temperatures, and high relative humidity. Thus, the maxima of the nucleation mode number concentration can be found in the upper tropical troposphere and in the remote regions of the Antarctic where convective detrainment and DMS conversion, respectively, provide sufficient sulfuric acid. Note that a large part of the nucleation mode particles 

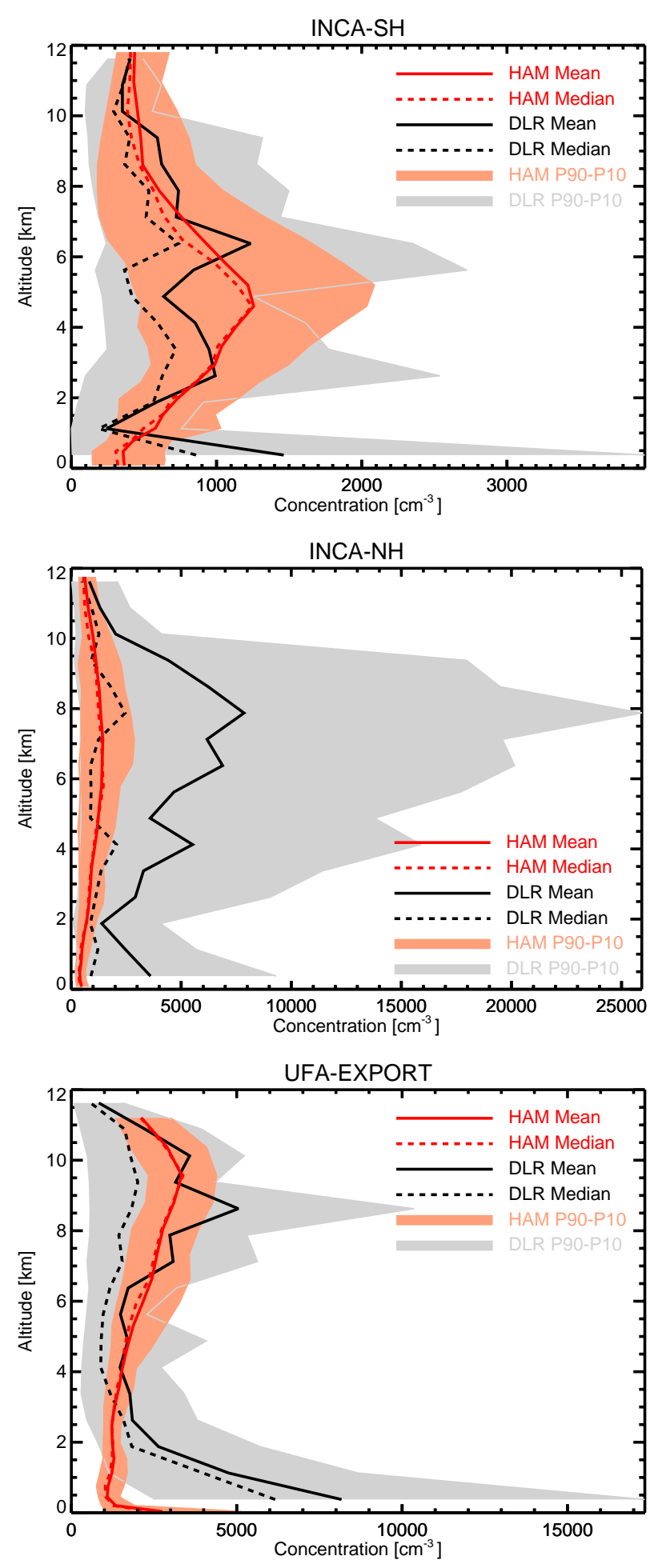

Fig. 5. Composite profiles of aerosol number-concentration $\left[\mathrm{cm}^{-3}\right.$ STP] from DLR aircraft measurements and ECHAM5-HAM for the INCA-SH, INCA-NH, and UFA-EXPORT measurement campaigns. ECHAM5-HAM results plotted in red, measurements in black, and the respective variability (P90-P10) in light red and gray. have radii below the typical detection limit of $3 \mathrm{~nm}$ of current measurement techniques.

Number concentrations of the insoluble Aitken mode are determined by primary emissions of BC and POM and therefore highest in the lower troposphere close to the source regions of biomass burning and anthropogenic emissions. The soluble Aitken mode numbers are dominated by particles growing from the nucleation in the Aitken size-range. Accumulation and coarse insoluble modes are externally mixed dust modes and reflect the zonal distribution of the dust emissions, with the largest contribution from the North African dust sources around $25^{\circ} \mathrm{N}$. Accumulation mode soluble numbers are highest in the lower troposphere between $30^{\circ} \mathrm{S}$ and $60^{\circ} \mathrm{N}$ close to the sources of biomass burning and fossil fuel use. Increased levels can also be found in the upper troposphere, attributable to convective detrainment of particles and their precursors. Coarse mode soluble particles are mainly confined to the lower troposphere and can mostly be attributed to sea salt emissions. Between $15^{\circ} \mathrm{N}$ and $20^{\circ} \mathrm{N} \mathrm{a}$ local maximum due to the contribution of aged dust particles is identifiable around $800 \mathrm{hPa}$.

To evaluate the simulated aerosol number concentrations, we compare them in Fig. 5 to vertical profiles obtained from aircraft measurements of the German Aerospace Agency (DLR). The measurements were conducted in the "Interhemispheric differences in cirrus properties from anthropogenic emissions" (INCA) experiments (Minikin et al., 2003) and the UFA2/EXPORT campaign (Petzold et al., in preparation ${ }^{2}$ ). To avoid ambiguities in the comparison with individual flight data, we compare campaign mean and median profiles of the simulation with campaign mean and median profiles of the measurements. The model data is averaged over the grid boxes containing the measurement domain. The model aerosol numbers are the superposition of the individual modes of HAM folded with the cut-off of the measurement instruments.

The first INCA campaign was conducted in southern Chile (INCA-SH) from (23/03/2000-14/04/2000) in the domain $\left(83.9^{\circ} \mathrm{W}-69.1^{\circ} \mathrm{W}, 58.5^{\circ} \mathrm{S}-51.0^{\circ} \mathrm{S}\right)$. The measured profile of aerosol numbers shows distinct maxima of median and mean in the mid-troposphere, between 2 and $7 \mathrm{~km}$. ECHAM5HAM well reproduces the vertical distribution of aerosol numbers. The underestimation in the lower boundary layer can be attributed to an underestimation of nucleation. The second INCA campaign was conducted in Scotland (INCA$\mathrm{NH})$ from $(27 / 09 / 2000-12 / 10 / 2000)$ in the domain $\left(8.7^{\circ} \mathrm{W}-\right.$ $\left.3.6^{\circ} \mathrm{E}, 54.6^{\circ} \mathrm{N}-61.2^{\circ} \mathrm{N}\right)$. The median particle concentration shows a homogeneous distribution throughout the troposphere and is well captured by the ECHAM5-HAM simulation. The observations show a large variability between

\footnotetext{
${ }^{2}$ A. Minikin, A. Petzold, M. Fiebig, J. Hendricks, and F. Schröder: Aerosol properties measured in situ in the free troposphere and tropopause region at midlatitudes, German Aerospace Agency DLR, Oberpfaffenhofen, Germany.
} 

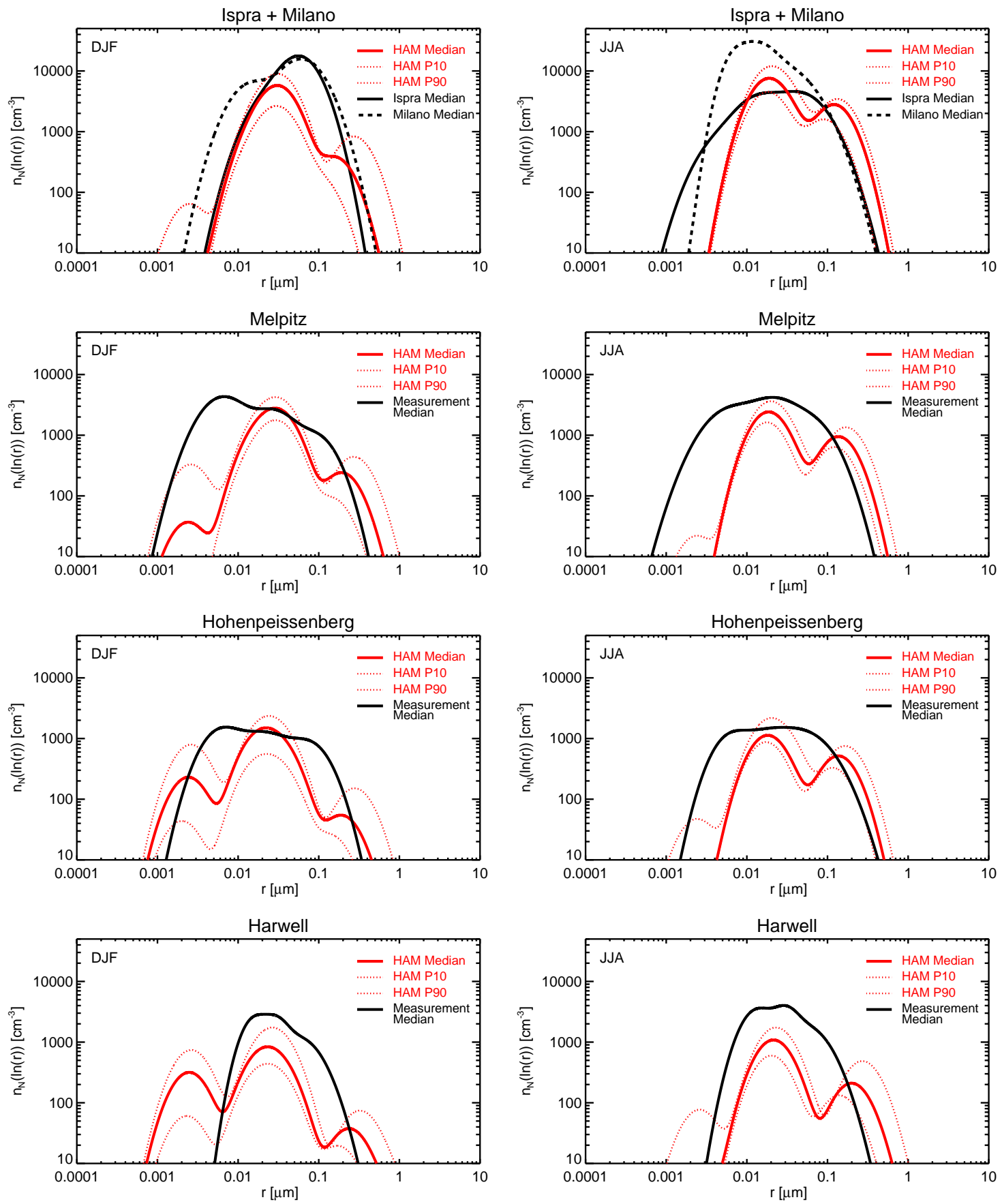

Fig. 6. Seasonal-mean dry aerosol number size-distributions [ $\left.\mathrm{cm}^{-3} \mathrm{STP}(1013.25 \mathrm{hPa}, 273.15 \mathrm{~K})\right]$ for December-January-February (DJF) and June-July-August (JJA) at the given locations. ECHAM5-HAM in red with medians as solid, and 10th (P10) and 90th (P90) percentiles as dotted line. Measurement medians (from Putaud et al., 2003) as black lines.

2 and $10 \mathrm{~km}$ due to singular convective detrainment of polluted plumes (A. Minikin, pers. comm.). These events are not reproduced in the simulation, leading to an underestimation of the model mean values in the free troposphere. Measurement over continental Europe were obtained during the UFA2/EXPORT campaign (19/07/2000-10/08/2000) in the domain $\left(5.3^{\circ} \mathrm{E}-28.8^{\circ} \mathrm{E}, 43.5^{\circ} \mathrm{N}-56.7^{\circ} \mathrm{N}\right)$. The observed $\mathrm{N}$ shows a distinct maximum in the boundary layer, a mid tropospheric minimum around $5 \mathrm{~km}$, and a second maximum between 7 and $11 \mathrm{~km}$. The ECHAM5-HAM simulated profile of $\mathrm{N}$ is in good agreement with the observations throughout most of the troposphere. However, the aerosol numbers 
in the lower boundary layer are under-predicted. Possible explanations are an underestimation of nucleation, a too efficient growth into larger size regimes, a too large emission size-distribution, underestimation of the emissions, or overestimated surface sinks. It has to be pointed out that as no simultaneous measurements of aerosol mass are available, it is not possible to further isolate one of those causes.

The simulated variability of $\mathrm{N}$, in terms of the difference of the 90th percentile (P90) and the 10th percentile (P10), for the polluted cases of UFA-EXPORT and INCA-NH is lower than in the measurements. In addition to the ambiguity of the comparison of grid-box mean values with local measurements, one explanation could be the usage of monthly mean emission data. The variability for the maritime southern hemispheric case INCA-SH, where interactively calculated natural emissions dominate, agrees well with the observations.

Simulated and measured dry aerosol number sizedistributions are compared in Fig. 6. Log-normally fitted median aerosol number size-distributions from a European surface measurements climatology for the period 1996 to 2001 (Putaud et al., 2003) have been averaged over the given morning and afternoon distributions as approximation of a daytime distribution. See Appendix B for a brief description of the measurement sites and Putaud et al. (2003) for a detailed description of the measurement compilation. The simulated size-distributions have been sampled at 12 UTC from the lowest model level grid-box containing the measurement location. Plotted are seasonal median and 10th and 90th percentiles size-distributions at standard atmospheric conditions for December-January-February (DJF) and JuneJuly-August (JJA). It has to be stressed that the comparison of a model grid-box mean size-distribution with local surface measurements is compromised by scale differences that inevitably lead to non-negligible deviations. This becomes evident in the evaluation of the size-distributions at the Ispra and Milano measurement sites that lie within the same model grid-box. The large differences between the measured size distributions at these sites is indicative for the, in the model non-resolvable, sub-grid-scale variability.

Generally, the simulated size distributions broadly reproduce the observed characteristics ranging from highly polluted urban (Milano), to polluted near-city (Ispra and Melpitz), and more pristine rural (Hohenpeissenberg and Harwell) conditions. For the Ispra and Milano sites, the high winter accumulation mode number-concentrations are underestimated while in summer the accumulation mode is shifted to larger radii at which it is biased high. For Melpitz the simulated Aitken and accumulation mode numbers are well captured, however, nucleation mode numbers are underestimated in winter and summer. Similar deviations are also found in the comparison to the Hohenpeissenberg measurements, although the model captures part of the nucleation peak in wintertime conditions. For Harwell, the simulated aerosol numbers are significantly biased low beside the over- estimation of wintertime nucleation. This can most likely be attributed to the fact that while the measurements are characteristic for local rural conditions, the model grid-box containing Harwell extends up to the coast and is not solely representable for the measurement conditions.

For all measurement sites, the nucleation mode numberconcentrations are underestimated in summer. This could be indicative of an overestimation of the condensational sink, an underestimation of the nucleation rate, or the importance of other nucleation pathways than the simulated binary nucleation, such as ternary or ion-induced nucleation or the contribution of organic vapours.

\subsection{Radiative properties}

Unlike the spatiotemporally constrained in-situ measurements, remote sensing data from satellites, supplemented by ground-based remote sensing, allows evaluating the model on a global scale. As the input parameters for the ECHAM5 radiation scheme are calculated by HAM explicitly in dependence of the size-distribution and composition of the modes, the resulting optical properties provide integrated information on the model performance. However, it should be kept in mind that remote sensing retrievals have uncertainties and maybe biased, in particular satellite retrievals of aerosol properties over land. Therefore, differences between model results and remote sensing products do not necessarily reflect model deficiencies.

The simulated field for the annual mean clear-sky aerosol optical depth (AOD) is displayed in Fig. 7a. The regions with highest values of the simulated AOD are the Saharan dust plume extending into the Atlantic, biomass burning regions of Central Africa, and Asian regions with strong anthropogenic contributions, particularly regions over China and India. The simulated global annual mean optical depth at 0.14 falls in the range suggested by other global models (0.116-0.155) participating in the AEROCOM model intercomparison (http://nansen.ipsl.jussieu.fr/AEROCOM/). The ECHAM5-HAM mean value is almost identical to a sampling bias corrected global average of AERONET (Kinne et al., in preparation ${ }^{3}$ ) of 0.14 . A similar corrected global annual average of the best available global data set, even so without coverage at high latitudes, a MODIS-MISR composite (see below), suggests a slightly larger value of about 0.16 . This agreement is encouraging in light of the many retrieval uncertainties and the likelihood of AOD overestimates due to errors in cloud-screening. While, a good quantitative agreement to data on a global annual basis is encouraging, matches for distribution pattern on a regional and seasonal basis are a more meaningful test.

In comparisons to AOD simulations of Fig. 7a, a measurement based AOD composite derived from advanced satellite

\footnotetext{
${ }^{3}$ An aerosol global climatology extending remote sensing from ground and space with data from global modeling, Max Planck Institute for Meteorology, Hamburg, Germany.
} 
(a) AOD ECHAM5-HAM
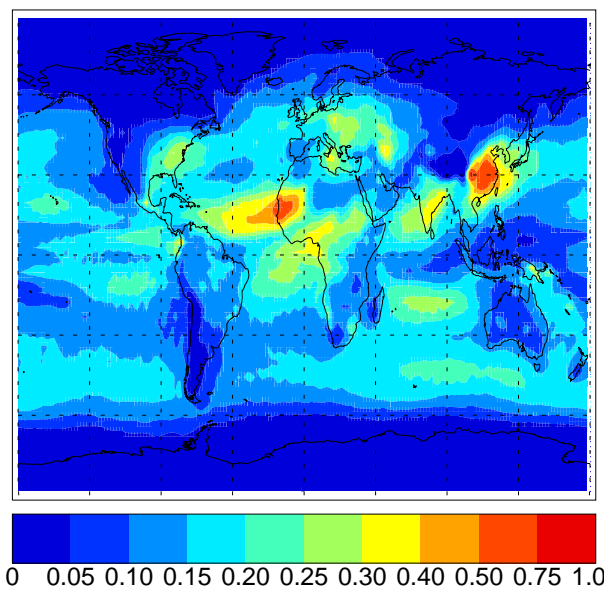

(c) ANG ECHAM5-HAM
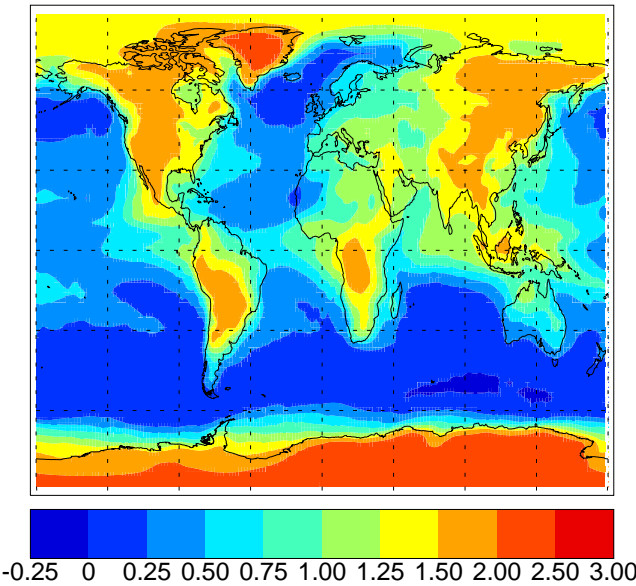

(b) AOD MISR+MODIS
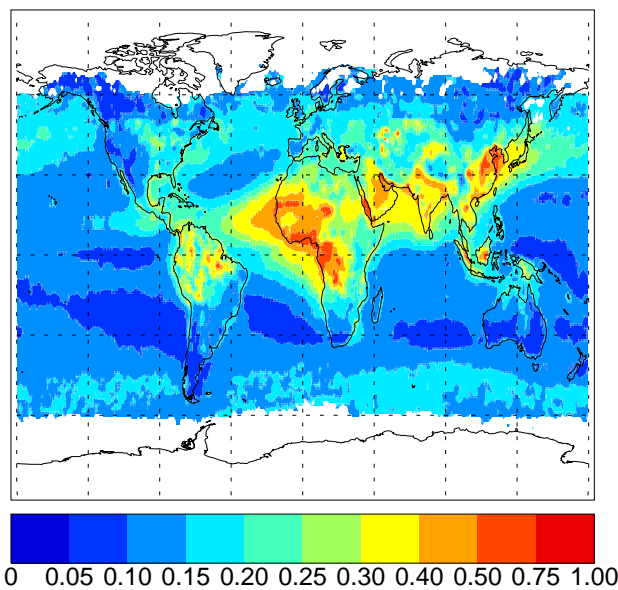

(d)

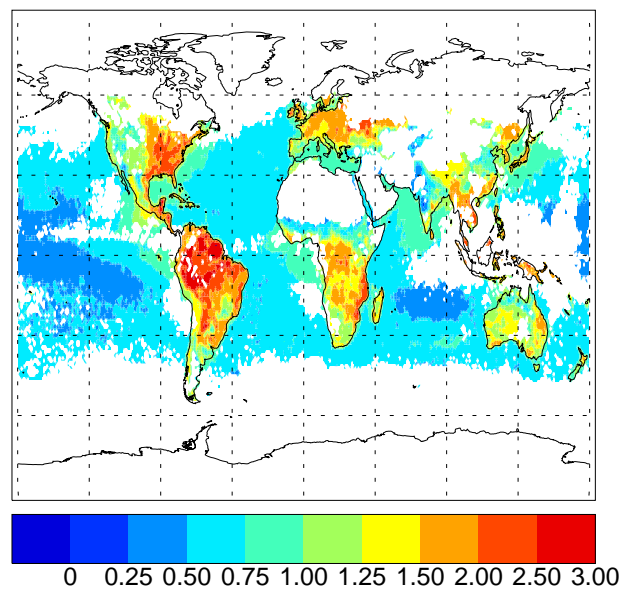

(e) ABS ECHAM5-HAM
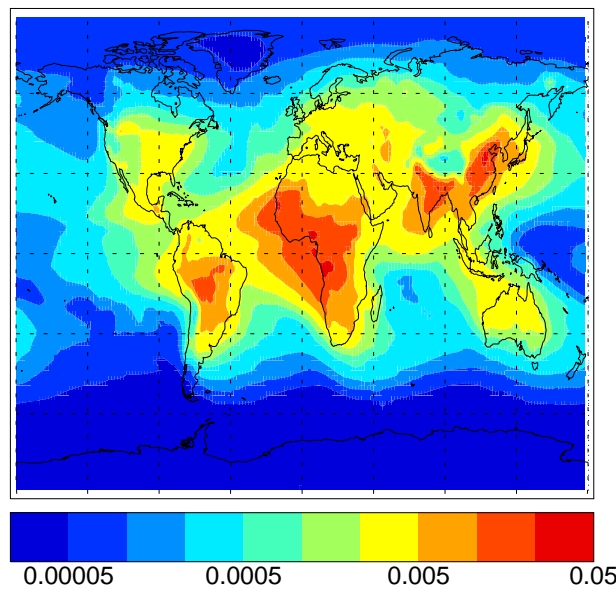

Fig. 7. Annual mean aerosol optical depth AOD simulated with ECHAM5-HAM, satellite retrieved annual (3/2000-2/2001) mean aerosol optical depth based on a composite of monthly averages of the MODIS and MISR sensors (MODIS over oceans and MISR over land), simulated $550 \mathrm{~nm} / 825 \mathrm{~nm}$ Ångström parameter ANG of ECHAM5-HAM, satellite retrieved ANG of MODIS (ocean: $550 \mathrm{~nm} / 865 \mathrm{~nm}$, land: $470 \mathrm{~nm} / 660 \mathrm{~nm}$ ), simulated absorption optical depth ABS of ECHAM5-HAM. ABS and AOD refer to a mid-visible wavelength $\lambda=550 \mathrm{~nm}$. 
retrievals is presented in Fig. 7b. This data-set comprises a composite of monthly means based on satellite retrievals between March 2000 and February 2001. It combines the strength of different retrievals applied to multi-spectral data of the MODIS and MISR sensors on NASA's EOS TERRA platform: Over water, data of the MODIS ocean retrieval (Tanré et al., 1997) are used, while over land the multidirectional retrieval of MISR (Martonchik et al., 2002), when available, is preferred over the MODIS land retrieval (Kaufman et al., 1997). MODIS and MISR derived aerosol properties were validated against AERONET sun-photometer measurements. AOD retrieval errors are estimated at $+/-0.04$ (at $10 \mathrm{~km}$ scales) for the MODIS ocean retrieval (Remer et al., 2002) and at $+/-0.05$ (at $50 \mathrm{~km}$ scales) for the MISR land retrieval (Martonchik et al., 2004). The land retrieval of the MODIS sensor is similar uncertain at $+/-0.1$ (at $10 \mathrm{~km}$ scales) (Chu et al., 2002), often displays a significant positive bias, and fails over vegetation-poor surfaces, such as deserts. Thus, even though MISR data are approximately 5 times less frequently sampled than MODIS, the monthly statistics of the MISR land retrieval is preferred. When comparing results of this possibly best data-set to model-simulations, it should be kept in mind that the data presented in Fig. 7b are associated with significant uncertainty, especially over land regions.

ECHAM5-HAM reproduces many patterns of the satellite composite. This includes large scale features, e.g. plumes from Asia into the Pacific or from Northern Africa into the Atlantic, as well as small scale features, e.g. the east-west AOD gradients over North America and Europe or the tongue of low optical depth extending northward of the Himalaya region. In a quantitative sense, the ECHAM5-HAM AODs tend to be larger over oceans and smaller over land and at high latitudes. Higher AODs, attributable to sea salt, are most pronounced in the oceanic storm track regions and in the secondary tropical source regions centred around $15^{\circ} \mathrm{N}$ and S. Lower AODs over land are most prominently found from Northern Africa to the Middle East and in northern South America. Based on AERONET AOD statistics, the discrepancy in South America is attributed to retrieval error resulting in an AOD overestimate, which also contradicts the expected clean "green ocean" regime with low optical depths over Amazonia (Andreae et al., 2004). However, the discrepancy over North Africa and the Middle East is most likely caused by dust AOD underestimates of the model.

Simulated AOD discrepancies to measurements are better illustrated in seasonal and regional comparisons. In Fig. 8 seasonal averaged AODs of ECHAM5-HAM are compared for 21 regions on a seasonal basis to four different measurement data-sets. AERONET (Holben et al., 2001), comprises (when present in selected regions) available (year 2000) AOD statistics of ground-based sun-photometry. MODISMISR represents the preferred satellite composite (3/20002/2001), which was already introduced in Fig. 6. These two data-sets are more relevant to the model simulations, be- cause they refer to the year 2000. The additional two datasets are provided as (historical) reference because they represent decadal statistics on tropospheric AOD (two-year periods following the El Chichon and Mt.Pinatubo eruptions were removed). TOMS (Torres et al., 2002) is based on UV reflectance data between 1979 and 2001, while AVHRR (Mishchenko et al., 1999) is based on visible/near-IR reflectance data between 1983 and 2001. Due to an uncertain surface contribution to the visible reflection, AVHRR retrieval are only provided for ocean regions. All data in Figure 7 refer to the mid-visible reference wavelength $\lambda=550 \mathrm{~nm}$.

Over oceans the MODIS retrieval is the best reference. The smallest pixel size helps support a better statistics and at the same time reduces the possibility of cloud contamination. Not surprisingly MODIS data display the lowest AOD values over oceans. ECHAM5-HAMs larger AOD for ocean regions in the tropics and during winter in the SH ocean regions suggests that sea salt AOD contributions are too large. Generally good AOD matches are found for off-source transport of dust and biomass over ocean regions, except for the North Pacific, where long-range transport from Asia is underestimated. Over land comparisons needs to take into account the larger uncertainty of the regional data, either related to accuracy issues of the satellite retrievals or related to a lack of regional representation for AERONET. For the land regions of the Americas and for Europe, AERONET is the preferred reference as there are sufficient stations in those regions. For all other regions the preferred reference is MISR. The at times large difference to the other land retrieval of TOMS, however, reduces confidence in the land retrievals. At large, there is a good agreement of simulated and retrieved regional AODs. For many regions, the simulated AODs lie within the range of the different retrievals. Focusing on the most pronounced differences, the ECHAM5HAM model underestimates dust AOD in the North AfricaMiddle East region. For the urban-industrial regions of the northern hemisphere the AOD contributions during fall and summer are often larger than the data. The biomass burning seasonal cycles in the (sub-) tropics are reproduced, although the strength of the biomass peak is underestimated, particularly in Southern Africa.

Satellite retrievals of the mid-visible Ångström parameter (ANG), defined as

$\mathrm{ANG}=\frac{\ln \mathrm{AOD}_{1}-\ln \mathrm{AOD}_{2}}{\ln \lambda_{2}-\ln \lambda_{1}}$

provide information on column integrated aerosol size. ANG values larger than 1.5 indicate that aerosol optical properties are dominated by the accumulation mode, whereas values smaller than 0.5 reflect a domination by coarse mode aerosol. Simulated ANG of ECHAM5-HAM are shown in Fig. 7c and a composite of MODIS land retrievals (Kaufman et al., 1997) and MODIS ocean retrievals (Tanré et al., 1997) is shown in Fig. 7d. Following the AOD accuracy assessment, MODIS ANG data over oceans are expected to be 

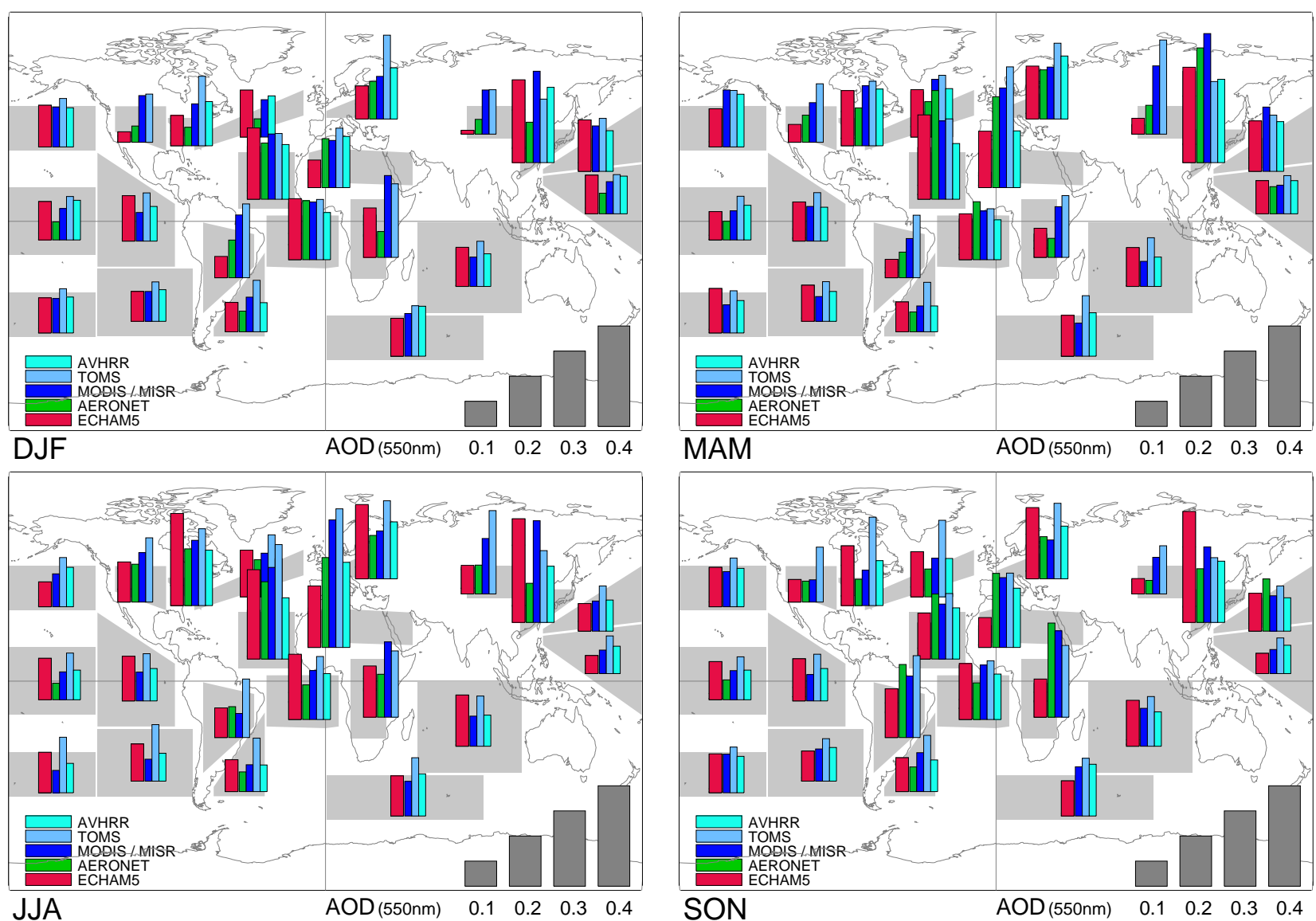

Fig. 8. Seasonal-mean aerosol optical depths $(\lambda=550 \mathrm{~nm})$ for December-January-February (DJF), March-April-May (MAM), June-JulyAugust (JJA), and September-October-November (SON) for selected regions (gray) for the year 2000. ECHAM5-HAM (red), AERONET (green), composite of MODIS over water and MISR over land (dark blue), TOMS (light blue), and AVHRR (turquoise).

more accurate than over land. In addition, as MODIS AOD land retrievals largely ignore coarse size mode contributions, thus MODIS ANG values over land are often biased high. The ECHAM5-HAM simulation shows the expected landsea contrast with higher ANG (smaller particles) over land and lower ANG (larger particles) over the oceans. While similar patterns and values for tropical oceans are matched by the model, there are also differences, particular over land regions at higher latitudes. Simulated higher ANG suggest smaller aerosol sizes over North America and Asia, although MODIS ANG could be biased low due to snow contamination. Over Europe smaller simulated ANG suggest larger aerosol sizes than indicated by data. Given the uncertainties in the MODIS ANG retrieval over land, however, it is not clear if these differences can be attributed to model deficiencies.

Aerosol absorption is an important parameter, as it determines the amount of solar heating by atmospheric aerosol, with potential implications to dynamics and the hydrological cycle. Aerosol absorption is commonly described by the aerosol absorption optical depth (ABS), which is defined by the product of the aerosol optical depth and the aerosol co-single-scattering albedo. Figure 7e displays the global distribution of the absorption optical depth simulated by ECHAM5-HAM. Highest values are found over the dust and biomass burning regions of Africa, the biomass burning regions of South America, and in the Asian regions with large anthropogenic activity, primarily regions in China and India. In the absence of global ABS measurements, we turned to aerosol absorption estimates from AERONET sky-radiation data inversion (Dubovik and King, 2000) for the year 2000. Monthly averages, which required a minimum of 10 inversions, were combined to seasonal averages. In Figure 9 these seasonal absorption averages are compared to ECHAM5HAM simulations for two seasons (DJF and JJA) at selected AERONET sites (see Appendix C). It should be noted that the AERONET absorption (since derived from sky-radiance data) carries a significant uncertainty with likely overestimates at low aerosol optical depths. Thus, there should be a focus on cases of larger optical depths. Good agreement 
for absorption is found for the dust outflow off the west coast of Africa and for the strength and seasonality of North America and of the biomass burning regions in the southern hemisphere. Otherwise the simulated absorption tends to be smaller than AERONET. The deficits in the Mid-East can most likely be related to AOD underestimates in that region. The underestimation over Europe could be a consequence of potentially underestimated sources of black carbon, as discussed by Schaap et al. (2004), or due to the assumption of a smaller imaginary part of the refractive index for POM than suggested by recent estimates (Kirchstetter et al., 2004).

In summary, the ECHAM5-HAM simulation of aerosol optical depth, size-distribution in terms of the Angström parameter, and absorption are in general agreement with remote sensing data from ground and space. While there is excellent AOD agreement for the global average, regional and seasonal analysis has shown that the ECHAM5-HAM overestimates sea salt contributions (particularly in the tropics and Southern oceans) and underestimates dust contributions (particularly in Northern Africa and the middle East). AODs in regions with strong anthropogenic contributions (particularly regions of Asia, Central to Eastern Europe, and the East Coast of North America) are generally well represented.

\section{Conclusions and Outlook}

The aerosol-climate modelling system ECHAM5-HAM, as part of the emerging Max Planck Earth System Model, is introduced. Embedded in the ECHAM5 GCM, the aerosol model HAM predicts the evolution of an ensemble of microphysically interacting internally- and externally-mixed aerosol populations. In the current setup, the components sulfate, black carbon, particulate organic matter, sea salt, and mineral dust are included. Advancing from the bulk modelling approach of most previous global aerosol models, the aerosol size-distribution, mixing state, and composition are described by prognostic variables. This facilitates the explicit calculation of aerosol optical properties for the radiation calculation, an explicit treatment of the sink processes, and provides the necessary input for the aerosol-cloud coupling.

The aerosol model includes the processes gas- and liquid phase sulfur chemistry, the sink processes dry deposition, sedimentation, and wet deposition, a radiation module, and the microphysical core M7. M7 considers the processes coagulation, condensation on pre-existing aerosols, aerosol nucleation, thermodynamical equilibrium with water vapour, and the inter-modal transfer. The emissions of dust, sea salt and maritime DMS are calculated online. For all other compounds, emissions are based on an emission inventory for the year 2000, taking into account injection heights and emission size-distributions.

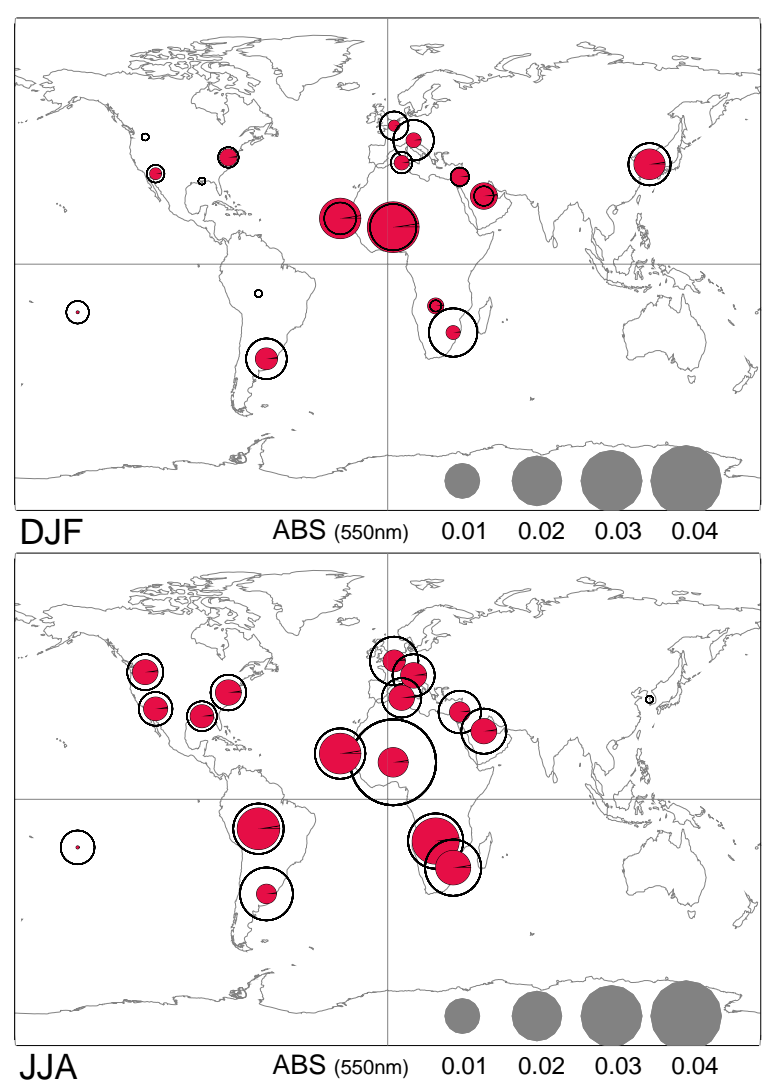

Fig. 9. Seasonal-mean absorption aerosol optical depth ABS $(\lambda=550 \mathrm{~nm})$ for December-January-February (DJF) and June-JulyAugust (JJA) at selected AERONET sites. ECHAM5-HAM is displayed with filled red circles, AERONET with black circle lines. The absorption optical depth is proportional to the area of the circles.

Despite the advanced complexity of ECHAM5-HAM, the computational efficiency allows the application in long-term climate studies.

Results of a one year nudged simulation for the year 2000 are presented. The global annual total emissions account to 95.2 $\mathrm{Tg}(\mathrm{S}) \mathrm{yr}^{-1}$ sulfuric compounds, 7.7 $\mathrm{Tg} \mathrm{yr}^{-1}$ black carbon, 66.3 $\mathrm{Tg} \mathrm{yr}^{-1}$ particulate organic matter, $5032 \mathrm{Tg} \mathrm{yr}^{-1}$ sea salt, as well as $662 \mathrm{Tg} \mathrm{yr}^{-1}$ and $787 \mathrm{Tg} \mathrm{yr}^{-1}$ dust for the Tegen et al. (2002) and Balkanski et al. (2004) emission schemes, respectively. Global annual-mean column burdens (lifetimes) of the compounds are: sulfate $0.80 \mathrm{Tg}(\mathrm{S})$ (3.9 days), black carbon $0.11 \mathrm{Tg}$ (5.4 days), particulate organic matter $0.99 \mathrm{Tg}$ (5.4 days), sea salt $10.5 \mathrm{Tg}$ (0.8 days), and dust $8.28 \mathrm{Tg}$ (4.6 days). The compounds in the insoluble modes undergo microphysical aging, due to coagulation with soluble modes and sulfate coating, resulting in aging times of 0.7 days for BC, 1.1 days for POM, and 4.8 days for DU.

The global sulfate column burden shows a pronounced export from Europe to northern Africa and the Middle East. Substantial exports of pollutants from Europe towards the 
Mediterranean and northern Africa have also been observed in the MINOS measurement campaign (Lelieveld et al., 2002). The distinct long-range transport of sulfate can most likely be attributed to lower dry deposition velocities for $\mathrm{SO}_{2}$ and sulfate over bare soils along the transport pathway. In contrast, most earlier studies assumed fixed dry deposition velocities over land surfaces. A large dust plume extending from North Africa into the Atlantic is the dominant feature of the dust distribution, secondary features are enhanced burdens over central Asia and Australia. Black carbon and particulate organic matter show large burdens in the vicinity of the biomass burning regions of Central Africa and South America, as well as in the regions with large anthropogenic activity, primarily near China and India. The dominant emissions of sea salt lie in the oceanic storm track regions. Compared to these emissions, the sea salt burden is high in the secondary source regions, centred around $15^{\circ} \mathrm{N}$ and S. Two factors account for this distribution as they result in high sinks coinciding with the source regions: First, the wet deposition is highest in the precipitation rich storm track regions. Second, the interactive calculation of the dry deposition velocities results in higher values in the oceanic storm tracks.

The evaluation of the simulated surface mass concentrations with measurements from the North American IMPROVE network, the European EMEP network, the Global Atmosphere Watch program, and a climatological compilation for remote sites by the University of Miami shows generally a good agreement, except for dust. The simulated sulfate mass agrees well with a slight tendency to overestimate, in particular over Europe. As the sink processes are treated globally uniform, the good agreement in North America and the overestimation over Europe could potentially indicate a positive bias of the European emissions. For BC the agreement is good with no discernible bias. Also for POM there is a good agreement, however, with low concentrations the simulated concentrations are increasingly underestimated. SS surface mass concentrations agree well at marine measurement sites. Low concentrations at continental sites are overestimated in the model, most likely due to numerical diffusion associated with the strong sea-land gradients. For dust, the comparison with the climatological dataset of the University of Miami reveals a general underestimation of surface mass concentrations for both, the Tegen et al. (2002) and Balkanski et al. (2004) emission schemes. Focusing only on the peak aerosol masses at stations with significant dust concentrations, the agreement is somewhat better. An analysis of the seasonality of the dust surface concentrations (not shown) reveals generally a good agreement. It has to be stressed that the inhomogeneous distribution of the measurement stations (12 out of 21 used stations lie in the Pacific and only 3 in the outflow region of the dominant North African dust sources) bias the scatter plots towards sites where the radiative impacts of dust are low or negligible. As the underestimation is particularly pronounced at remote sites (see Table 4) the neglect of the super-coarse mode, with a short lifetime, appears not to be the main cause of the bias. This leaves a too low emission strength, in particular of the Asian dust sources, or an overestimation of the wet deposition as the most likely causes. The wet deposition is highly sensitive to two assumptions: First, the microphysical aging time depends on the required amount of sulfate to assume particles as coated. The current choice of a mono-layer of sulfate needs to be scrutinised in laboratory studies. Second, the scavenging parameters $R$ are subject of large uncertainties. Even though measurements for individual cloud events are available, the translation to different aerosol types, to the grid-box scale and finally to the global scale, is highly uncertain. Further sensitivity studies will be carried out to investigate the sensitivity to the different assumptions.

Total simulated aerosol numbers are dominated by secondary particle formation. Highest number concentrations are found in the upper troposphere. Primary emissions dominate the accumulation and coarse mode sizes, largely confined to the low to mid troposphere. Simulated number concentrations are evaluated with campaign composite aircraft measurement data from three year 2000 measurement campaigns. For the maritime influenced southern hemispheric INCA-SH and northern hemispheric INCA-NH campaigns, the simulation nicely reproduces the vertical profiles of the median number concentration with maxima in the mid troposphere. For the continental UFA/EXPORT campaign, the number concentrations in the boundary layer are underestimated, however, the low values in the mid troposphere and the maximum between 7 and $12 \mathrm{~km}$ are in good agreement with the observations.

Simulated aerosol number size-distributions broadly reproduce the observed characteristics for a range of evaluated conditions from European surface measurement sites. Nonetheless, non-negligible deviations are found. Most of these differences are not attributable to specific processes as they could also be attributed to sub-grid scale variability and uncertainties in the local-scale emissions. However, a persistent feature at all sites is the underestimation of simulated nucleation mode number concentrations in summer. This could be indicative of an overestimation of the condensational sink but could also be explained by the importance of other nucleation pathways than the simulated binary sulfate/water nucleation.

The predominant features of the simulated aerosol optical depth are the Saharan dust plume extending into the Atlantic, outflow regions of Central African biomass burning, Asian regions with strong anthropogenic pollution, and oceanic regions attributable to the contribution of sea salt aerosol. The simulated global average of aerosol optical depth is with 0.14 in very good agreement with estimates from remote sensing products (AERONET derived global average: 0.14, MODISMISR composite: 0.16 ) and falls within the range of estimates of other modelling studies (0.116-0.155) participating in the AEROCOM inter-comparison. The comparison of the AOD with remote sensing products on the regional 
scale reveals that the contribution by dust is underestimated, particularly in North-Eastern Africa, the Middle East, and East Asia extending into the Pacific outflow region. This is also the cause of an underestimation of absorption during the dust season, compared to Middle East AERONET measurements. Further it is consistent with the negative bias of the surface mass concentrations. The remote oceanic AODs are generally higher than the remote sensing data, suggesting an overestimation of the sea salt aerosol optical depth. This could either be a consequence of overestimated sea salt burdens, of an overestimated water uptake, or of a mismatch of the ambient size-distribution, resulting in a too high extinction cross section. However, the fact that the evaluation of the sea salt water uptake calculated by M7 with a more complex thermodynamical model revealed an overestimation at relative humidities between $45 \%$ and $75 \%$ (Vignati et al., 2004), suggests this bias as an important contribution to the overestimation. The underestimation of AODs at high latitudes of North America and Asia, together with the relatively good agreement of the surface mass concentrations of the in this regions predominant POM, could potentially indicate the effect of the neglect of water uptake by carbonaceous aerosols.

The presented results are part of an ongoing long-term research activity in which the ECHAM5-HAM aerosol climate model and the underlying parameterisations are further evaluated with increasing availability of suitable observational data.

The microphysical approach of ECHAM5-HAM, minimising the number of externally imposed parameters, is a major achievement. For example, most previous parameterisations used in indirect aerosol effect studies (see Penner et al. (2001)) rely on empirical relations that might not be applicable for different climatic regimes. The extension of the prognostic parameter space in ECHAM5-HAM to include size distribution, composition, mixing state provides the basis for a microphysical coupling of the aerosol and cloud schemes. ECHAM5-HAM has already been extended by an advanced cloud microphysical scheme with explicit treatment of cloud droplet number concentration and ice crystal number concentration (Lohmann et al., 1999a; Lohmann and Kärcher, 2002). This setup provides the fundament for future studies of the semi-direct and indirect aerosol radiative effects. The explicit treatment of the aerosol activation will also allow to reduce the uncertainty associated with the scavenging parameters and render the investigation of aerosolcloud interaction in a GCM possible. However, the explicit treatment of aerosol-cloud interactions, in particular considering the ice phase, is a long-term effort that requires the development and improvement of suitable parameterisations. A sound experimental basis is required to be established in future laboratory and in-situ measurement studies.

Optionally, instead of the reduced sulfur chemistry scheme implemented in HAM, the full MOZART chemistry scheme (Horowitz et al., 2003) is available in ECHAM5, allowing for studies of heterogeneous chemistry and aerosol-chemistry interactions. In the framework of the EU project PHOENICS (http://phoenics.chemistry.uoc.gr), an extended thermodynamical module (Metzger et al., 2002) is being coupled with M7 in ECHAM5 and will be merged into the ECHAM5HAM model. This development will, together with the MOZART chemistry scheme, establish the basis for the inclusion of the currently neglected nitrate/ammonium system and considerably improve the accuracy of the water uptake calculations. Also within PHOENICS, a condensed version of a comprehensive secondary organic aerosol model (Tsigaridis and Kanakidou, 2003), computationally efficient for long-term simulations, is in development. 
Appendix A: List of surface measurement stations used in Fig. 3

Sulfate

List of sulfate measurement sites used in Fig. 3 and corresponding statistics.

\begin{tabular}{|c|c|c|c|c|c|c|c|}
\hline Location & Longitude & Latitude & $\begin{array}{r}\text { Model } \\
\text { Annual Mean } \\
{\left[\mu \mathrm{g} \mathrm{m}^{-3}\right]}\end{array}$ & $\begin{array}{r}\text { Measurement } \\
\text { Annual Mean } \\
{\left[\mu \mathrm{g} \mathrm{m}^{-3}\right]}\end{array}$ & $\begin{array}{r}\text { Model } \\
\text { Standard } \\
\text { Deviation }\end{array}$ & $\begin{array}{r}\text { Measurement } \\
\text { Standard } \\
\text { Deviation }\end{array}$ & $\begin{array}{r}\text { Total } \\
\text { Number } \\
\text { Measurements }\end{array}$ \\
\hline \multicolumn{8}{|l|}{ EMEP Network } \\
\hline Aliartos & 23.1 & 38.4 & 6.1 & 2.8 & 3.09 & 1.19 & 100 \\
\hline Anholt & 11.5 & 56.7 & 3.7 & 2.5 & 3.36 & 1.49 & 355 \\
\hline Aspvretren & 17.4 & 58.8 & 1.2 & 0.7 & 1.18 & 0.96 & 91 \\
\hline Birkenes & 8.2 & 58.4 & 1.9 & 1.3 & 2.35 & 1.31 & 364 \\
\hline Danki & 37.8 & 54.9 & 6.8 & 1.7 & 5.44 & 1.33 & 326 \\
\hline DiablaGora & 22.1 & 54.2 & 5.4 & 2.4 & 4.51 & 2.05 & 354 \\
\hline Eskdalemuir & -3.2 & 55.3 & 2.1 & 1.3 & 2.04 & 1.08 & 344 \\
\hline HighMuffles & -0.8 & 54.3 & 3.1 & 1.8 & 2.58 & 1.32 & 358 \\
\hline Jarczew & 22.0 & 51.3 & 7.6 & 4.7 & 5.24 & 2.31 & 360 \\
\hline Keldsnor & 10.7 & 54.7 & 3.9 & 3.0 & 3.04 & 1.69 & 360 \\
\hline Kolummerwaard & 6.3 & 53.3 & 3.9 & 1.9 & 3.19 & 1.28 & 316 \\
\hline Kpuszta & 19.5 & 50.0 & 8.3 & 5.0 & 5.59 & 3.13 & 349 \\
\hline Leba & 17.5 & 54.8 & 5.3 & 3.7 & 4.25 & 2.18 & 366 \\
\hline Montelibretti & 12.6 & 42.1 & 5.3 & 3.2 & 4.27 & 1.71 & 345 \\
\hline Neuglobsow & 13.0 & 53.2 & 4.8 & 3.2 & 4.61 & 2.45 & 338 \\
\hline Oulanka & 29.4 & 66.3 & 1.3 & 1.2 & 1.72 & 0.97 & 364 \\
\hline Preila & 21.2 & 55.3 & 4.7 & 2.8 & 4.30 & 1.82 & 360 \\
\hline Roervik & 11.9 & 57.4 & 3.2 & 2.2 & 2.98 & 2.19 & 361 \\
\hline Rucava & 21.2 & 56.2 & 4.2 & 0.8 & 3.60 & 0.83 & 366 \\
\hline Shepeljovo & 29.1 & 60.0 & 4.2 & 0.4 & 2.92 & 0.34 & 345 \\
\hline Skrealaden & 6.7 & 58.8 & 1.5 & 1.1 & 2.32 & 1.20 & 343 \\
\hline Tange & 9.6 & 56.3 & 3.2 & 2.4 & 2.92 & 1.43 & 327 \\
\hline Uto & 21.4 & 59.8 & 3.4 & 1.8 & 2.78 & 1.30 & 366 \\
\hline Vavihill & 13.1 & 56.0 & 3.8 & 2.3 & 3.63 & 1.84 & 361 \\
\hline Vreedepeel & 5.8 & 51.5 & 4.1 & 2.3 & 2.91 & 1.66 & 334 \\
\hline \multicolumn{8}{|l|}{ IMPROVE Network } \\
\hline Acadia & -68.3 & 44.4 & 2.4 & 1.6 & 2.12 & 1.35 & 97 \\
\hline Badlands & -101.9 & 43.7 & 2.2 & 1.0 & 1.74 & 0.63 & 89 \\
\hline Bandelier & -106.3 & 35.8 & 2.4 & 0.8 & 1.60 & 0.39 & 103 \\
\hline Big Bend & -103.2 & 29.3 & 3.2 & 2.1 & 2.22 & 1.28 & 83 \\
\hline Boundary Waters & -91.5 & 48.0 & 1.1 & 1.0 & 1.46 & 0.66 & 61 \\
\hline Denali & -149.0 & 63.7 & 0.2 & 0.3 & 0.18 & 0.26 & 77 \\
\hline Everglades & -80.7 & 25.4 & 1.7 & 2.7 & 1.52 & 2.63 & 56 \\
\hline Gila Wilderness & -108.2 & 33.2 & 2.2 & 0.9 & 1.60 & 0.48 & 66 \\
\hline Mammoth Cave & -86.3 & 37.3 & 6.5 & 4.8 & 4.42 & 3.34 & 99 \\
\hline Mount Rainier & -122.1 & 46.8 & 1.8 & 0.8 & 1.44 & 0.69 & 103 \\
\hline Okefenokee & -82.1 & 30.7 & 4.2 & 3.9 & 2.81 & 2.34 & 95 \\
\hline Virgin Island & -64.8 & 18.3 & 0.6 & 1.1 & 0.44 & 0.41 & 38 \\
\hline \multicolumn{8}{|l|}{ University of Miami Network } \\
\hline Chatham Island - New Zealand & -176.5 & -43.9 & 0.4 & 0.3 & & & \\
\hline Cape Point - South Africa & 18.5 & -34.3 & 1.5 & 0.6 & & & \\
\hline Cape Grim - Tasmania & 144.7 & -40.7 & 0.6 & 0.3 & & & \\
\hline Invercargill - New Zealand & 168.4 & -46.4 & 0.3 & 0.4 & & & \\
\hline Marsh - King George Island & -58.3 & -62.2 & 0.4 & 0.3 & & & \\
\hline Marion Island & 37.8 & -46.9 & 0.3 & 0.1 & & & \\
\hline Mawson - Antarctica & 62.5 & -67.6 & 0.1 & 0.1 & & & \\
\hline Palmer Station - Antarctica & -64.1 & -64.8 & 0.3 & 0.1 & & & \\
\hline Reunion Island & 55.8 & -21.2 & 0.3 & 0.4 & & & \\
\hline Wellington - New Zealand & 174.9 & -41.3 & 0.5 & 0.4 & & & \\
\hline Yate - New Caledonia & 167.0 & -22.1 & 0.5 & 0.4 & & & \\
\hline Funafuti - Tuvalu & -179.2 & -8.5 & 0.4 & 0.2 & & & \\
\hline Nauru & 166.9 & -0.5 & 0.6 & 0.2 & & & \\
\hline Norfolk Island & 168.0 & -29.1 & 0.3 & 0.3 & & & \\
\hline Rarotonga - Cook Islands & -159.8 & -21.2 & 0.2 & 0.1 & & & \\
\hline American Samoa & -170.6 & -14.2 & 0.2 & 0.3 & & & \\
\hline Midway Island & -177.4 & 28.2 & 0.3 & 0.5 & & & \\
\hline Oahu Hawaii & -157.7 & 21.3 & 0.4 & 0.5 & & & \\
\hline Cheju - Korea & 126.5 & 33.5 & 7.8 & 7.2 & & & \\
\hline Hedo Okinawa - Japan & 128.2 & 26.9 & 5.1 & 4.3 & & & \\
\hline Fanning Island & -159.3 & 3.9 & 0.4 & 0.6 & & & \\
\hline Enewetak Atoll & 162.3 & 11.3 & 0.3 & 0.1 & & & \\
\hline Barbados & -59.4 & 13.2 & 0.4 & 0.7 & & & \\
\hline Izana Tenerife & -16.5 & 28.3 & 1.6 & 1.0 & & & \\
\hline Bermuda & -64.9 & 32.3 & 1.1 & 2.1 & & & \\
\hline Heimaey Iceland & -20.3 & 63.4 & 0.4 & 0.7 & & & \\
\hline Mace Head - Ireland & -9.9 & 53.3 & 1.4 & 1.3 & & & \\
\hline Miami & -80.2 & 25.8 & 2.0 & 2.2 & & & \\
\hline \multicolumn{8}{|l|}{ GAW Network } \\
\hline Hohenpeissenberg & 11.0 & 47.8 & 3.4 & 1.6 & 2.65 & 0.98 & 224 \\
\hline
\end{tabular}


Black Carbon

List of black carbon measurement sites used in Fig. 3 and corresponding statistics.

\begin{tabular}{lrrrrrrr}
\hline Location & Longitude & Latitude & $\begin{array}{r}\text { Model } \\
\text { Annual Mean } \\
{\left[\mu \mathrm{g} \mathrm{m}^{-3}\right]}\end{array}$ & $\begin{array}{r}\text { Measurement } \\
\text { Annual Mean } \\
{\left[\mu \mathrm{g} \mathrm{m}^{-3}\right]}\end{array}$ & $\begin{array}{r}\text { Model } \\
\text { Standard } \\
\text { Deviation }\end{array}$ & $\begin{array}{r}\text { Measurement } \\
\text { Standard } \\
\text { Deviation }\end{array}$ & $\begin{array}{r}\text { Total } \\
\text { Number } \\
\text { Measurements }\end{array}$ \\
\hline IMPROVE Network & & & & & & & \\
Acadia & -68.3 & 44.4 & 0.2 & 0.2 & 0.18 & 0.16 & 99 \\
Badlands & -101.9 & 43.7 & 0.2 & 0.2 & 0.10 & 0.15 & 90 \\
Bandelier & -106.3 & 35.8 & 0.2 & 0.3 & 0.07 & 0.69 & 104 \\
Big Bend & -103.2 & 29.3 & 0.1 & 0.2 & 0.06 & 0.11 & 83 \\
Boundary Waters & -91.5 & 48.0 & 0.1 & 0.2 & 0.16 & 0.17 & 61 \\
Denali & -149.0 & 63.7 & 0.0 & 0.1 & 0.02 & 0.17 & 104 \\
Everglades & -80.7 & 25.4 & 0.1 & 0.3 & 0.06 & 0.21 & 56 \\
Gila Wilderness & -108.2 & 33.2 & 0.2 & 0.3 & 0.05 & 0.55 & 66 \\
Mammoth Cave & -86.3 & 37.3 & 0.5 & 0.5 & 0.22 & 0.28 & 99 \\
Mount Rainier & -122.1 & 46.8 & 0.6 & 0.3 & 0.48 & 0.22 & 104 \\
Okefenokee & -82.1 & 30.7 & 0.2 & 0.5 & 0.13 & 0.51 & 97 \\
Virgin Island & -64.8 & 18.3 & 0.0 & 0.0 & 0.01 & 0.05 & 38 \\
\hline
\end{tabular}

Organic Matter

List of organic matter measurement sites used in Fig. 3 and corresponding statistics.

\begin{tabular}{lrrrrrr}
\hline Location & Longitude & Latitude & $\begin{array}{r}\text { Model } \\
\text { Annual Mean } \\
{\left[\mu \mathrm{g} \mathrm{m}^{-3}\right]}\end{array}$ & $\begin{array}{r}\text { Measurement } \\
\text { Annual Mean } \\
{\left[\mu \mathrm{g} \mathrm{m}^{-3}\right]}\end{array}$ & $\begin{array}{r}\text { Model } \\
\text { Standard } \\
\text { Deviation }\end{array}$ & $\begin{array}{r}\text { Measurement } \\
\text { Standard } \\
\text { Deviation }\end{array}$ \\
\hline IMPROVE Network & & & & & & $\begin{array}{r}\text { Total } \\
\text { Number }\end{array}$ \\
Acadia & & & & & & \\
Badlands & -68.3 & 44.4 & 0.9 & 1.1 & 1.04 & 0.50 \\
Bandelier & -101.9 & 43.7 & 0.8 & 1.4 & 0.74 & 1.15 \\
Big Bend & -106.3 & 35.8 & 0.9 & 1.0 & 0.65 & 4.44 \\
Boundary Waters & -103.2 & 29.3 & 0.9 & 1.0 & 0.86 & 0.72 \\
Denali & -91.5 & 48.0 & 0.7 & 0.7 & 0.23 & 0.77 \\
Everglades & -149.0 & 63.7 & 0.2 & 1.0 & 0.40 & 2.46 \\
Gila Wilderness & -80.7 & 25.4 & 0.5 & 2.0 & 0.53 & 0.57 \\
Mammoth Cave & -108.2 & 33.2 & 0.8 & 2.3 & 1.57 & 3.10 \\
Mount Rainier & -86.3 & 37.3 & 2.1 & 1.2 & 1.47 & 1.77 \\
Okefenokee & -122.1 & 46.8 & 1.7 & 2.5 & 1.50 & 0.89 \\
Virgin Island & -82.1 & 30.7 & 2.3 & 0.4 & 0.05 & 2.56 \\
\hline
\end{tabular}

\section{Dust}

List of dust measurements sites used in Fig. 3 and corresponding statistics.

\begin{tabular}{lrrrr}
\hline Location & Longitude & Latitude & $\begin{array}{r}\text { Model } \\
\text { Annual Mean } \\
{\left[\mu \mathrm{g} \mathrm{m}^{-3}\right]}\end{array}$ & $\begin{array}{r}\text { Measurement } \\
\text { Annual Mean } \\
{\left[\mu \mathrm{g} \mathrm{m}^{-3}\right]}\end{array}$ \\
& & & & \\
\hline University of Miami Network & & & 0.49 & 2.20 \\
Cape Point - South Africa & 18.5 & -34.3 & 0.0006 & 0.52 \\
Marsh - King George Island & -58.3 & -62.2 & 0.0002 & 0.10 \\
Mawson - Antarctica & 62.5 & -67.6 & 0.0002 & 0.35 \\
Palmer Station - Antarctica & -64.1 & -64.8 & 1.09 & 0.17 \\
Yate - New Caledonia & 167.0 & -22.1 & 0.01 & 0.19 \\
Funafuti - Tuvalu & -179.2 & -8.5 & 0.01 & 0.10 \\
Nauru & 166.9 & -0.5 & 1.21 & 0.84 \\
Norfolk Island & 168.0 & -29.1 & 0.04 & 0.11 \\
Rarotonga - Cook Islands & -159.8 & -21.2 & 0.01 & 0.16 \\
American Samoa & -170.6 & -14.2 & 0.04 & 0.72 \\
Midway Island & -177.4 & 28.2 & 0.01 & 0.66 \\
Oahu Hawaii & -157.7 & 21.3 & 3.16 & 14.14 \\
Cheju - Korea & 126.5 & 33.5 & 1.46 & 8.37 \\
Hedo Okinawa - Japan & 128.2 & 26.9 & 0.01 & 0.10 \\
Fanning Island & -159.3 & 3.9 & 0.01 & 0.24 \\
Enewetak Atoll & 162.3 & 11.3 & 6.89 & 14.48 \\
Barbados & -59.4 & 13.2 & 22.12 & 30.18 \\
Izana Tenerife & -16.5 & 28.3 & 0.61 & 3.36 \\
Bermuda & -64.9 & 32.3 & 0.37 & 1.00 \\
Mace Head - Ireland & -9.9 & 53.3 & 1.25 & 4.59 \\
Miami & -80.2 & 25.8 & & \\
\hline & & & & \\
\hline
\end{tabular}


Sea Salt

List of sea salt measurement sites used in Fig. 3 and corresponding statistics.

\begin{tabular}{|c|c|c|c|c|c|c|c|}
\hline Location & Longitude & Latitude & $\begin{array}{r}\text { Model } \\
\text { Annual Mean } \\
{\left[\mu \mathrm{g} \mathrm{m}^{-3}\right]}\end{array}$ & $\begin{array}{r}\text { Measurement } \\
\text { Annual Mean } \\
{\left[\mu \mathrm{g} \mathrm{m}^{-3}\right]}\end{array}$ & $\begin{array}{r}\text { Model } \\
\text { Standard } \\
\text { Deviation }\end{array}$ & $\begin{array}{r}\text { Measurement } \\
\text { Standard } \\
\text { Deviation }\end{array}$ & $\begin{array}{r}\text { Total } \\
\text { Number } \\
\text { Measurements }\end{array}$ \\
\hline \multicolumn{8}{|l|}{ IMPROVE Network } \\
\hline Acadia & -68.3 & 44.4 & 6.5 & 0.6 & 6.60 & 0.93 & 99 \\
\hline Badlands & -101.9 & 43.7 & 0.2 & 0.0 & 0.23 & 0.07 & 88 \\
\hline Bandelier & -106.3 & 35.8 & 0.3 & 0.0 & 0.34 & 0.05 & 97 \\
\hline Big Bend & -103.2 & 29.3 & 1.7 & 0.2 & 1.79 & 0.38 & 81 \\
\hline Boundary Waters & -91.5 & 48.0 & 1.0 & 0.1 & 1.03 & 0.16 & 61 \\
\hline Denali & -149.0 & 63.7 & 0.5 & 0.1 & 1.24 & 0.17 & 104 \\
\hline Everglades & -80.7 & 25.4 & 10.1 & 1.0 & 10.06 & 0.80 & 56 \\
\hline Gila Wilderness & -108.2 & 33.2 & 0.8 & 0.1 & 1.09 & 0.12 & 57 \\
\hline Mammoth Cave & -86.3 & 37.3 & 0.8 & 0.2 & 1.45 & 0.35 & 99 \\
\hline Mount Rainier & -122.1 & 46.8 & 2.7 & 0.2 & 3.89 & 0.26 & 105 \\
\hline Okefenokee & -82.1 & 30.7 & 4.8 & 0.7 & 4.55 & 0.75 & 100 \\
\hline Virgin Island & -64.8 & 18.3 & 13.9 & 1.7 & 7.43 & 1.23 & 38 \\
\hline \multicolumn{8}{|l|}{ University of Miami Network } \\
\hline Chatham Island - New Zealand & -176.5 & -43.9 & 27.3 & 13.8 & & & \\
\hline Cape Point - South Africa & 18.5 & -34.3 & 18.3 & 10.4 & & & \\
\hline Cape Grim - Tasmania & 144.7 & -40.7 & 22.6 & 19.8 & & & \\
\hline Invercargill - New Zealand & 168.4 & -46.4 & 20.9 & 7.1 & & & \\
\hline Marsh - King George Island & -58.3 & -62.2 & 18.1 & 3.5 & & & \\
\hline Marion Island & 37.8 & -46.9 & 45.6 & 10.5 & & & \\
\hline Mawson - Antarctica & 62.5 & -67.6 & 0.8 & 0.3 & & & \\
\hline Palmer Station - Antarctica & -64.1 & -64.8 & 9.1 & 3.2 & & & \\
\hline Reunion Island & 55.8 & -21.2 & 23.2 & 11.6 & & & \\
\hline Wellington - New Zealand & 174.9 & -41.3 & 15.7 & 10.4 & & & \\
\hline Yate - New Caledonia & 167.0 & -22.1 & 18.0 & 31.9 & & & \\
\hline Norfolk Island & 168.0 & -29.1 & 19.0 & 26.0 & & & \\
\hline American Samoa & -170.6 & -14.2 & 9.5 & 5.5 & & & \\
\hline Midway Island & -177.4 & 28.2 & 17.7 & 14.3 & & & \\
\hline Oahu Hawaii & -157.7 & 21.3 & 21.1 & 14.9 & & & \\
\hline Cheju - Korea & 126.5 & 33.5 & 11.5 & 16.4 & & & \\
\hline Hedo Okinawa - Japan & 128.2 & 26.9 & 15.4 & 23.3 & & & \\
\hline Fanning Island & -159.3 & 3.9 & 17.7 & 14.8 & & & \\
\hline Barbados & -59.4 & 13.2 & 21.5 & 17.4 & & & \\
\hline Izana Tenerife & -16.5 & 28.3 & 20.1 & 0.0 & & & \\
\hline Bermuda & -64.9 & 32.3 & 16.0 & 13.4 & & & \\
\hline Heimaey Iceland & -20.3 & 63.4 & 14.3 & 25.7 & & & \\
\hline Mace Head - Ireland & -9.9 & 53.3 & 18.4 & 19.8 & & & \\
\hline Miami & -80.2 & 25.8 & 10.6 & 8.5 & & & \\
\hline \multicolumn{8}{|l|}{ GAW Network } \\
\hline Hohenpeissenberg & 11.0 & 47.8 & 1.5 & 0.4 & 3.53 & 0.56 & 224 \\
\hline
\end{tabular}

\section{Appendix B: List of Surface Measurement Sites Used in Fig. 6}

List of surface measurement sites used in Fig. 6.

\begin{tabular}{lrrrr}
\hline Location & Longitude & Latitude & $\begin{array}{r}\text { Altitude } \\
\text { [m a.s.1.] }\end{array}$ & Category \\
& & & & \\
\hline Milano-Bresso (I) & 45.53 & 9.20 & 130 & Urban \\
Ispra (I) & 45.82 & 8.63 & 209 & Near-City \\
Melpitz (D) & 51.53 & 12.93 & 86 & Near-City \\
Hohenpeissenberg (D) & 47.80 & 11.02 & 988 & Rural \\
Harwell (GB) & 51.57 & -1.32 & 125 & Rural \\
\hline
\end{tabular}


Appendix C: List of AERONET Measurement Sites Used in Fig. 9

List of AERONET measurement stations used in Fig. 9.

\begin{tabular}{lll}
\hline Location & Longitude & Latitude
\end{tabular}

\begin{tabular}{lrr}
\hline AERONET Network & & \\
Abracos Hill & -62.4 & -10.8 \\
Anmyon & 126.3 & 36.5 \\
Banizombou & 2.7 & 13.5 \\
Cap Verde & -22.9 & 16.7 \\
Ceilap & -58.5 & -34.6 \\
El Arenosillo & 6.7 & 37.1 \\
Goddard & -106.1 & 53.9 \\
Lille & 3.1 & 50.6 \\
Maricopa & -112.0 & 33.1 \\
Mongu & -15.3 & 23.2 \\
Nes Ziona & 34.8 & 31.9 \\
Rimrock & -117.0 & 46.5 \\
Skukusa & 31.6 & -25.0 \\
Solar Village & 46.4 & 24.9 \\
Stennis & -89.6 & 30.4 \\
Tahiti & -149.6 & -17.6 \\
Venice & 12.5 & 45.3 \\
\hline
\end{tabular}

Acknowledgements. We wish to thank J. Prospero and D. Savoie (University of Miami) for providing the compilation of multi-annual surface observations and to B. Holben (NASA Goddard) for the use of the AERONET data. Many thanks also to R. van Dingenen (JRC, Ispra) for helping us with the size-distribution measurements and to S. Guilbert (LSCE, Gif-sur-Yvette) for her help with the handling of the IMPROVE, EMEP, and GAW datasets. We are also grateful to M. Schultz (MPI for Meteorology, Hamburg) for providing the MOZART chemistry fields. F. Dentener (JRC, Ispra) is to be thanked for his support with the emission data and many helpful discussions. Our thanks extend to our colleagues (MPI for Meteorology, Hamburg) L. Kornblueh, S. Rast, A. Rhodin, E. Roeckner, and U. Schulzweida for their constant support with the ECHAM5HAM model development, and to R. Hommel and C. Timmreck for fruitful discussions about the aerosol module and the help with the nucleation parameterisation. U. Koerner (DKRZ, Hamburg) is to be thanked for the support with the code optimisation. We would also like to acknowledge the support of the German DEKLIM project, of the International Max Planck Research School for Earth System Modelling, and of the EU project PHOENICS (EVK2-CT-200100098).

Edited by: B. Kärcher

\section{References}

Adams, P. J. and Seinfeld, J. H.: Predicting global aerosol size distributions in general circulation models, J. Geophys. Res., 107, 4370, doi:10.1029/2001JD001 010, 2002.

Albrecht, B. A.: Aerosols, cloud microphysics, and fractional cloudiness, Science, 245, 1227-1230, 1989.

Andreae, M. and Crutzen, P.: Atmospheric aerosols: biogeochemical sources and role in atmospheric chemistry, Science, 276, 1052-1058, 1997.

Andreae, M. O., Rosenfeld, D., Artaxo, P., Costa, A. A., Frank, G. P., Longo, K. M., and Silva-Diass, M. A. F.: Smoking rain clouds over the Amazon, Science, 303, 1337-1342, 2004.

Andres, R. J. and Kasgnoc, A. D.: A time-averaged inventory of subaerial volcanic sulfur emissions, J. Geophys. Res., 103, 25 251-25 261, 1998.

Ångström, A.: Atmospheric turbidity, global illumination and planetary albedo of the earth, Tellus, 14, 435-450, 1962.

Balkanski, Y., Schulz, M., Claquin, T., Moulin, C., and Ginoux, P.: Emission Of Atmospheric Trace Compounds, chap. Global emissions of mineral aerosol: formulation and validation using satellite imagery, pp. 239-267, Ed. Kluwer, 2004.

Bates, T. S., Huebert, B. J., Gras, J. L., Griffiths, F. B., and Durkee, P. A.: International Global Atmospheric Chemistry (IGAC) project's first Aerosol Characterisation Experiment (ACE 1): overview., J. Geophys. Res., 103, 16 297-16318, 1998.

Bond, T. C., Streets, D. G., Yarber, K. F., Nelson, S. M., Woo, J.H., and Klimont, Z.: A technology-based global inventory of black and organic carbon emissions from combustion, J. Geophys. Res., 109, D14 203, doi:10.1029/2003JD003 697, 2004.

Chin, M., Jacob, D. J., Gardner, G. M., Foreman-Fowler, M. S., Spiro, P. A., and Savoie, D. L.: A global three-dimensional model of tropospheric sulfate, J. Geophys. Res., 101, 18667 $18690,1996$.

Chin, M., Ginoux, P., Kinne, S., Torres, O., Holben, B. N., Duncan, B. N., Martin, R. V., Logan, J. A., Higurashi, A., and Nakajima, T.: Tropospheric aerosol optical thickness from the GOCART model and comparisons with satellite and Sun photometer measurements, J. Atmos. Sci., 59, 461-483, 2002.

Chu, D. A., Kaufman, Y. J., Ichoku, C., Remer, L. A., Tanré, D., and Holben, B. N.: Validation of MODIS aerosol optical depth retrieval over land, Geophys. Res. Lett., 29, 8007, doi:10.1029/2001GL013 205, 2002.

Chung, S. H. and Seinfeld, J. H.: Global distribution and climate forcing of carbonaceous aerosols, J. Geophys. Res., 107, 4407, doi:10.1029/2001JD001397, 2002.

Claquin, T.: Modeling of the mineralogy and the radiative forcing of desert dust, Ph.D. thesis, Paris University, Paris, France, 1999.

Cofala, J., Amann, M., and Mechler, R.: Scenarios of world anthropogenic emissions of air pollutants and methane up to 2030, Tech. rep., International Institute for Applied Systems Analysis (IIASA), Laxenburg, Austria, available from: http://www.iiasa. ac.at/rains/global_emiss/global_emiss.html, 2005.

Crutzen, P.: Nucleation of atmospheric aerosols, chap. The role of particulate matter in ozone photochemistry, pp. 268-270, Elsevier, 1996.

Dentener, F. and Crutzen, P.: Reaction of $\mathrm{N}_{2} \mathrm{O}_{5}$ on tropospheric aerosols - impact on the global distributions of $\mathrm{NO}_{\mathrm{x}}, \mathrm{O}_{3}$, and OH, J. Geophys. Res., 98, 7149-7163, 1993. 
Downing, H. D. and Williams, D.: Optical-constants of water in infrared, J. Geophys. Res., 80, 1656-1661, 1975.

Dubovik, O. and King, M. D.: A flexible inversion algorithm for retrieval of aerosol optical properties from sun and sky radiance measurements, J. Geophys. Res., 105, 20 673-20 696, 2000.

Feichter, J., Kjellström, E., Rodhe, H., Dentener, F., Lelieveld, J., and Roelofs, G.-J.: Simulation of the tropospheric sulfur cycle in a global climate model, Atmos. Environ., 30, 1693-1707, 1996.

Feichter, J., Roeckner, E., Lohmann, U., and Liepert, B.: Nonlinear aspects of the climate response to greenhouse gas and aerosol forcing, J. Clim., 17, 2384-2398, 2004.

Fouquart, Y. and Bonnel, B.: Computations of solar heating of the earth's atmosphere: A new parameterization, Beitr. Phys. Atmos., 53, 35-62, 1980.

Fuchs, N. A.: Evaporation and droplet growth in gaseous media, Pergamon, Tarrytown, New York, 72 pp., 1959.

Fuchs, N. A.: The mechanics of aerosols, Pergamon Press, Oxford, 1964.

Gallagher, M. W., Nemitz, E., Dorsey, J. R., Fowler, D., Sutton, M. A., and andand J. Duyzer, M. F.: Measurements and parameterizations of small aerosol deposition velocities to grassland, arable crops, and forest: Influence of surface roughness length on deposition, J. Geophys. Res., 107, 4154, doi:10.1029/2001JD000 817, 2002.

Ganzeveld, L. and Lelieveld, J.: Dry deposition parameterization in a chemistry general circulation model and its influence on the distribution of reactive trace gases, J. Geophys. Res., 100, 20 999-21 012, 1995.

Ganzeveld, L., Lelieveld, J., and Roelofs, G.-J.: Dry deposition parameterization of sulfur oxides in a chemistry and general circulation model, J. Geophys. Res., 103, 5679-5694, 1998.

Ghan, S., Laulainen, N., Easter, R., Wagener, R., Nemesure, S., Chapman, E., and Leung, Y. Z. R.: Evaluation of aerosol direct radiative forcing in MIRAGE, J. Geophys. Res., 106, 52955316, 2001a.

Ghan, S. J., Easter, R. C., Hudson, J., and Brèon, F.-M.: Evaluation of aerosol indirect radiative forcing in MIRAGE, J. Geophys. Res., 106, 5317-5334, 2001b.

Gong, S. L., Barrie, L. A., and Lazare, M.: Canadian Aerosol Module (CAM): A size-segregated simulation of atmospheric aerosol processes for climate and air quality models 2 . Global sea-salt aerosol and its budgets, J. Geophys. Res., 107, 4779, doi:10.1029/2001JD002 004, 2002.

Gong, S. L., Barrie, L. A., Blanchet, J. P., K. von Salzen, U. L., Lesins, G., Spacek, L., Zhang, L. M., Girard, E., Lin, H., Leaitch, R., Leighton, H., Chylek, P., and Huang, P.: Canadian Aerosol Module: A size-segregated simulation of atmospheric aerosol processes for climate and air quality models - 1. Module development, J. Geophys. Res., 108, 4007, doi:10.1029/2002JD002 633, 2003.

Graßl, H.: Albedo reduction and radiative heating of clouds by absorbing aerosol particles, Contributions Atmospheric Physics, 48, 199-210, 1975.

Guelle, W., Schulz, M., Balkanski, Y., and Dentener, F.: Influence of the source formulation on modeling the atmospheric global distribution of sea salt aerosol, J. Geophys. Res., 106, 27 50927 524, 2001.

Guenther, A., Hewitt, C. N., Erickson, D., Fall, R., Geron, C., Graedel, T., Harley, P., Klinger, L., Lerdau, M., McKay, W. A.,
Pierce, T., Scholes, B., Steinbrecher, R., Tallamraju, R., Taylor, J., and Zimmerman, P.: A global model of natural volatile organic compound emissions, J. Geophys. Res., 100, 8873-8892, 1995.

Gutman, G., Tarpley, D., Ignatov, A., and Olson, S.: The enhanced NOAA global land dataset from Advanced Very High Resolution Radiometer, Bull. Am. Meteorol. Soc., 76, 1141-1156, 1995.

Halmer, M. M., Schmincke, H.-U., and Graf, H.-F.: The annual volcanic gas input into the atmosphere, in particular into the stratosphere: a global data set for the past 100 years, Journal of Volcanology and Geothermal Research, 115, 511-528, 2002.

Hansen, J., Sato, M., and Ruedy, R.: Radiative forcing and climate response, J. Geophys. Res., 102, 6831-6864, 1997.

Haywood, J. M., Ramaswamy, V., and Donner, L. J.: A limitedarea-model case study of the effects of sub-grid scale variations in relative humidity and cloud upon the direct radiative forcing of sulfate aerosol, Geophys. Res. Lett., 24, 143-146, 1997a.

Haywood, J. M., Roberts, D. L., Slingo, A., Edwards, J. M., and Shine, K. P.: General circulation model calculations of the direct radiative forcing by anthropogenic sulfate and fossil-fuel soot aerosol, J. Clim., 10, 1562-1577, 1997b.

Heintzenberg, J., Raes, F., Schwartz, S., Ackermann, I., Artaxo, P., Bates, T., Benkovitz, C., Bigg, K., Bond, T., Brenguier, J., Eisele, F., Feichter, J., Flossmann, A., Fuzzi, S., Graf, H., Hales, J., Herrmann, H., Hoffmann, T., Huebert, B., Husar, R., Jaenicke, R., Kärcher, B., Kaufman, Y., Kent, G., Kulmala, M., Leck, C., Liousse, C., Lohmann, U., Marticorena, B., Mcmurry, P., Noone, K., Dowd, C., Penner, J., Pszenny, A., Putaud, J., Quinn, P., Schurath, U., Seinfeld, J., Sievering, H., Snider, J., Sokolik, I., Stratmann, F., Dingenen, R. V., Westphal, D., Wexler, A., Wiedensohler, A., Winkler, D., and Wilson, J.: Atmospheric Chemistry in a Changing World, An Integration and Synthesis of a Decade of Tropospheric Chemistry Research, chap. Tropospheric Aerosols, pp. 125-156, Global Change - The IGBP Series, Springer, Berlin Heidelberg New York, 2003.

Henning, S., Bojinski, S., Diehl, K., Ghan, S., Nyeki, S., Weingartner, E., Wurzler, S., , and Baltensperger, U.: Aerosol partitioning in natural mixed-phase clouds, Geophys. Res. Lett., 31, L06 101, doi:10.1029/2003GL019 025, 2004.

Hess, M., Koepke, P., and Schult, I.: Optical properties of aerosols and clouds: The software package OPAC, Bull. Am. Meteorol. Soc., 79, 831-844, 1998.

Holben, B. N., Tanré, D., Smirnov, A., Eck, T. F., Slutsker, I., Abuhassan, N., Newcomb, W. W., Schafer, J. S., Chatenet, B., Lavenu, F., Kaufman, Y. J., Castle, J. V., Setzer, A., Markham, B., Frouin, D. C. R., Halthore, R., Karneli, A., O’Neill, N. T., Pietras, C., Pinker, R. T., Voss, K., and Zibordi, G.: An emerging ground-based aerosol climatology: Aerosol optical depth from AERONET, J. Geophys. Res., 106, 12 067-12 098, 2001.

Horowitz, L. W., Walters, S., Mauzerall, D. L., Emmons, L. K., Rasch, P. J., Granier, C., Tie, X., Lamarque, J.-F., Schultz, M. G., Tyndall, G. S., Orlando, J. J., and Brasseur, G. P.: A global simulation of tropospheric ozone and related tracers: Description and evaluation of MOZART, version 22, J. Geophys. Res., 108, 4784, doi:10.1029/2002JD002 853, 2003.

Hsu, N. C., Herman, J. R., Torres, O., Holben, B. N., Tanre, D., Eck, T. F., Smirnov, A., Chatenet, B., and Lavenu, F.: Comparisons of the TOMS aerosol index with Sun-photometer aerosol optical thickness: Results and applications, J. Geophys. Res., 104, 
6269-6280, 1999.

Hummelshøj, P., Jensen, N. O., and Larsen, S. E.: Particle dry deposition to a sea surface, pp. 829-840, Precipitation scavenging and atmosphere-surface exchange, Hemisphere Publishing Corporation, Washington, 1992.

Jacobson, M. Z.: GATOR-GCMM: A global-through urban-scale air pollution and weather forecast model, 1. Model design and treatment of subgrid soil, vegetation, roads, rooftops, water, sea ice, and snow, J. Geophys. Res., 106, 5385-5402, 2001.

Jacobson, M. Z., Tabazadeh, A., and Turco, R. P.: Simulating equilibrium within aerosols and nonequilibrium between gases and aerosols, J. Geophys. Res., 101, 9079-9091, 1996.

Johnson, K., Gordon, R., and Coale, K.: What controls dissolved iron concentrations in the world ocean?, Marine Chemistry, 57, 137-161, 1997.

Kaufman, Y. J., Tanré, D., Remer, L. A., Vermote, E. F., Chu, A., and Holben, B. N.: Operational remote sensing of tropospheric aerosol over land from EOS moderate resolution imaging spectroradiometer, J. Geophys. Res., 102, 17 051-17 068, 1997.

Kettle, A. and Andreae, M.: Flux of the dimethylsulfide from the oceans: A comparison of updated data sets and flux models, J. Geophys. Res., 105, 26 793-26 808, 2000.

Kinne, S., Lohmann, U., Feichter, J., Schulz, M., Timmreck, C., Ghan, S., Easter, R., Chin, M., Ginoux, P., Takemura, T., Tegen, I., Koch, D., Herzog, M., Penner, J., Pitari, G., Holben, B., Eck, T., Smirnov, A., Dubovik, O., Slutsker, I., Tanre, D., Torres, O., Mishchenko, M., Geogdzhayev, I., Chu, D. A., and Kaufman, Y.: Monthly averages of aerosol properties: A global comparison among models, satellite data, and AERONET ground data, J. Geophys. Res., 108, 4634, doi:10.1029/2001JD001 253, 2003.

Kirchstetter, T., Novakov, T., and Hobbs, P.: Evidence that the spectral dependence of light absorption by aerosols is affected by organic carbon, J. Geophys. Res., 109, D21 208, doi:10.1029/2004JD004 999, 2004.

Koepke, P., Hess, M., Schult, I., and Shettle, E.: Global Aerosol Data Set, Report 243, Max Planck Institute for Meteorology, Hamburg, ISSN 0937-1060, 1997.

Kulmala, M., Laaksonen, A., and Pirjola, L.: Parameterizations for sulfuric acid/water nucleation rates, J. Geophys. Res., 103, 83018307, 1998.

Langner, J. and Rhode, H.: A global three-dimensional model of the global sulfur cycle, J. Atmos. Chem., 13, 225-263, 1991.

Lelieveld, J., Berresheim, H., Borrmann, S., Crutzen, P. J., Dentener, F. J., Fischer, H., Feichter, J., Flatau, P. J., Heland, J., Holzinger, R., Korrmann, R., Lawrence, M. G., Levin, Z., Markowicz, K. M., Mihalopoulos, N., Minikin, A., Ramanathan, V., de Reus, M., Roelofs, G. J., Scheeren, H. A., Sciare, J., Schlager, H., Schultz, M., Siegmund, P., Steil, B., Stephanou, E. G., Stier, P., Traub, M., Warneke, C., Williams, J., and Ziereis, H.: Global air pollution crossroads over the mediterranean, Science, 298, 794-799, doi:10.1126/science.1075457, 2002.

Lesins, G., Chylek, P., and Lohmann, U.: A study of internal and external mixing scenarios and its effect on aerosol optical properties and direct radiative forcing, J. Geophys. Res., 107, 4094, doi:10.1029/2001JD000 973, 2002.

Liepert, B. G., Feichter, J., Lohmann, U., and Roeckner, E.: Can aerosols spin down the water cycle in a warmer and moister world?, Geophys. Res. Lett., 31, L06207, doi:10.1029/2003GL019 060, 2004.
Lin, S. J. and Rood, R. B.: Multidimensional flux form semiLagrangian transport, Mon. Wea. Rev., 124, 2046-2068, 1996.

Lohmann, U.: A glaciation indirect aerosol effect caused by soot aerosols, Geophys. Res. Lett., 29, 1052, doi:10.1029/2001GL014 357, 2002.

Lohmann, U. and Feichter, J.: Impact of sulfate aerosols on albedo and lifetime of clouds: A sensitivity study with the ECHAM4 GCM, J. Geophys. Res., 102, 13 685-13 700, 1997.

Lohmann, U. and Kärcher, B.: First interactive simulations of cirrus clouds formed by homogeneous freezing in the ECHAM general circulation model, J. Geophys. Res., 107, 4105, doi:10.1029/2001JD000 767, 2002.

Lohmann, U. and Roeckner, E.: Design and performance of a new cloud microphysics scheme developed for the ECHAM4 general circulation model, Clim. Dyn., 12, 557-572, 1996.

Lohmann, U., Feichter, J., Chuang, C. C., and Penner, J. E.: Predicting the number of cloud droplets in the ECHAM-GCM, J. Geophys. Res., 104, 9169-9198, 1999a.

Lohmann, U., von Salzen, K., McFarlane, N., Leighton, H. G., and Feichter, J.: Tropospheric sulfur cycle in the Canadian general circulation model, J. Geophys. Res., 104, 26 833-26 858, 1999 b.

Marticorena, B. and Bergametti, G.: Modeling the atmospheric dust cycle: 1. Design of a soil-derived dust emission scheme, J. Geophys. Res., 100, 16415-16430, 1995.

Martonchik, J., Diner, D., Crean, K., and Bull, M.: Regional aerosol retrieval results from MISR, IEEE Trans. Geosci. Remote Sens., 40, 1520-1531, 2002.

Martonchik, J., Diner, D., Kahn, R., Gaitley, B., and Holben, B.: Comparison of MISR and AERONET aerosol optical depths over desert sites, Geophys. Res. Lett., 31, L16 102, doi:10.1029/2004GL019 807, 2004.

Mayol-Bracero, M.-O., Guyon, P., Graham, B., Roberts, G., Andreae, M., Decesari, S., Facchini, M., Fuzzi, S., and Artaxo, P.: Water-soluble organic compounds in biomass burning aerosols over Amazonia - 2. Apportionment of the chemical composition and importance of the polyacidic fraction, J. Geophys. Res.Atmos., 107, 8091, doi:10.1029/2001JD000 522, 2002.

McCormic, R. A. and Ludwig, J. H.: Climate modifications by atmospheric aerosols, Science, 156, 1358-1359, 1967.

Metzger, S., Dentener, F., Pandis, S., and Lelieveld, J.: Gas/aerosol partitioning, 1, A computationally efficient model, J. Geophys. Res., 107, 4312, doi:10.1029/2001JD001 102, 2002.

Minikin, A., Petzold, A., Strom, J., Krejci, R., Seifert, M., van Velthoven, v. P., Schlager, H., and Schumann, U.: Aircraft observations of the upper tropospheric fine particle aerosol in the Northern and Southern Hemispheres at midlatitudes, Geophys. Res. Lett., 30, 1503, doi:10.1029/2002GL016 458, 2003.

Mishchenko, M. I., Geogdzhayev, I. V., Cairns, B., Rossow, W. B., and Lacis, A. A.: Aerosol retrievals over the ocean by use of channels 1 and 2 AVHRR data: sensitivity analysis and preliminary results, Appl. Opt., 38, 7325-7341, 1999.

Mlawer, E. J., Taubman, S. J., Brown, P. D., Iacono, M. J., and Clough, S. A.: Radiative transfer for inhomogeneous atmospheres: RRTM, a validated correlated-k model for the longwave, J. Geophys. Res., 102, 16 663-16 682, 1997.

Monahan, E., Spiel, D., and Davidson, K.: Oceanic whitecaps and their role in air-sea exchange, chap. A model of marine aerosol generation via whitecaps and wave disruption, pp. 167-174, D. Reidel, Norwell, Massachusetts, 1986. 
Morcrette, J.-J., Clough, S. A., Mlawer, E. J., and Iacono, M. J.: Impact of a validated radiative transfer scheme, RRTM, on the ECMWF model climate and 10-day forecasts, ECMWF, Reading, UK, technical memorandum 252 edn., 1998.

Moulin, C., Dulac, F., Lambert, C. E., Chazette, P., Janowiak, I., Chatenet, B., and Lavenu, F.: Long-term daily monitoring of Saharan dust load over ocean using Meteosat ISCCP-B2 data, 2, Accuracy of the method and validation using Sun photometer measurements, J. Geophys. Res., 102, 16 959-16969, 1997.

Murphy, D. M., Thomson, D. S., Middlebrook, A. M., and Schein, M. E.: In situ single-particle characterization at Cape Grim, J. Geophys. Res., 103, 16485-16491, 1998.

Nightingale, P., Malin, G., Law, C., Watson, A., Liss, P., Liddicoat, M., Boutin, J., and Upstill-Goddard, R.: In situ evaluation of airsea gas exchange parameterizations using novel conservative and volatile tracers, Global Biogeochem. Cycles, 14, 373-387, 2000.

Nordeng, T. E.: Extended versions of the convective parameterization scheme at ECMWF and their impact on the mean and transient activity of the model in the tropics, ECMWF, Reading, UK, technical memorandum edn., 1994.

Olson, J.: World ecosystems (WE1.4): Digital raster data on a 10 minute geographic 1080 (2160 grid square), Global Ecosystem Database, Version 1.0: DISC A, edited by NOAA National Geophysical Data Center, Boulder, CO, 1992.

Penner, J. E., Andreae, M., Annegarn, H., Barrie, L., Feichter, J., Hegg, D., Jayaraman, A., Leaitch, R., Murphy, D., Nganga, J., and Pitari, G.: Climate change 2001: the scientific basis, chap. Aerosols, their direct and indirect effects, pp. 298-248, Cambridge University Press, 2001.

Pham, M., J.-F.Muller, Brasseur, G., Granier, C., and Megie, G.: A three-dimensional study of the tropospheric sulfur cycle, J. Geophys. Res., 100, 26061-26092, 1995.

Putaud, J., van Dingenen, R., Baltensperger, U., Bruggemann, E., Charron, A., Facchini, M., Decesari, S., Fuzzi, S., Gehrig, R., H. H.-C., Harrison, R. M., Jones, A. M., Laj, P., Lorbeer, G., Maenhaut, W., Mihalopoulos, N., Müller, K., Palmgren, F., Querol, X., Rodriguez, S., Schneider, J., Spindler, G., ten Brink, H., Tunved, P., Torseth, K., Wehner, B., Weingartner, E., Wiedensohler, A., Wahlin, P., and Raes, F.: A european aerosol phenomenology, Report EUR 20411 EN, European Comission Joint Research Centre, Ispra, Italy, available from: http://carbodat.ei.jrc.it/ccu/, 2003.

Ramanathan, V., Crutzen, P. J., Kiehl, J. T., and Rosenfeld, D.: Aerosols, climate, and the hydrological cycle, Science, 294, 2119-2124, 2001.

Rasch, P. J., Barth, M. C., Kiehl, J. T., Schwartz, S. E., and Benkovitz, C. M.: A description of the global sulfur cycle and its controlling processes in the National Center for Atmospheric Research Community Climate Model, J. Geophys. Res., 105, 13671386, 2000.

Ravishankara, A. R.: Heterogeneous and multiphase chemistry in the troposphere, Science, 276, 1058-1066, 1997.

Remer, L. A., , Tanré, D., Kaufman, Y. J., Ichoku, C., Mattoo, S., Levy, R., Chu, D. A., Holben, B., Dubovik, O., Smirnov, A., Martins, J. V., Li, R. R., and Ahmad, Z.: Validation of MODIS aerosol retrieval over ocean, Geophys. Res. Lett., 29, 8008, doi:10.1029/2001GL013 204, 2002.

Roeckner, E., Baeuml, G., Bonventura, L., Brokopf, R., Esch, M., Giorgetta, M., Hagemann, S., Kirchner, I., Kornblueh,
L., Manzini, E., Rhodin, A., Schlese, U., Schulzweida, U., and Tompkins, A.: The atmospheric general circulation model ECHAM5. PART I: Model description, Report 349, Max Planck Institute for Meteorology, Hamburg, Germany, available from http://www.mpimet.mpg.de, 2003.

Roelofs, G.-J., Lelieveld, J., and Ganzeveld, L.: Simulation of global sulfate distribution and the influence on effective cloud drop radii with a coupled photochemistry sulfur cycle model, Tellus B, 50, 224-242, 1998.

Schaap, M., Gon, H. A. C. D. V. D., Dentener, F. J., Visschedijk, A. J. H., Loon, M. V., ten Brink, H. M., Putaud, J.-P., Guillaume, B., Liousse, C., and Builtjeses, P. J. H.: Anthropogenic black carbon and fine aerosol distribution over Europe, J. Geophys. Res., 109, D18 207, doi:10.1029/2003JD004 330, 2004.

Schulz, M., Balkanski, Y. J., Guelle, W., and Dulac, F.: Role of aerosol size distribution and source location in a three dimensional simulation of a Saharan dust episode tested against satellite-derived optical thickness, J. Geophys. Res., 103, 10 579-10 592, 1998.

Schulz, M., de Leeuw, G., and Balkanski, Y.: Emission Of Atmospheric Trace Compounds, chap. Sea-salt aerosol source functions and emissions, pp. 333-359, Ed. Kluwer, 2004.

Seinfeld, J. H. and Pandis, S. N.: Atmospheric chemistry and physics: from air pollution to climate change, WileyInterscience, 1998.

Seinfeld, J. H., Carmichael, G. R., Arimoto, R., Conant, W. C., Brechtel, F. J., Bates, T. S., Cahill, T. A., Clarke, A. D., Doherty, S. J., Flatau, P. J., Huebert, B. J., Kim, J., Markowicz, K. M., Quinn, P. K., Russell, L. M., Russell, P. B., Shimizu, A., Shinozuka, Y., Song, C. H., Tang, Y. H., Uno, I., Vogelmann, A. M., Weber, R. J., Woo, J. H., and Zhang, X. Y.: ACE-ASIA - Regional climatic and atmospheric chemical effects of Asian dust and pollution, Bull. Am. Meteorol. Soc., 85, 367-380, 2004.

Shettle, E. P. and Fenn, R. W.: Models of the aerosols of the lower atmosphere and the effects of humidity variations on their optical properties, Tech. rep., Air Force Geoph. Lab., Massachusetts, project 7670, 1979.

Simmons, A. J. and Gibson, J. K.: The ERA-40 project plan, ERA40 Project Report Series 1, ECMWF, Shinfield Park, Reading, UK, 2000.

Slinn, S. A. and Slinn, W. G. N.: Predictions for particle deposition on natural waters, Atmos. Environ., 14, 1013-1016, 1980.

Slinn, W. G. N.: Atmosphere-surface exchange of particulate and gaseous pollutants, chap. Dry deposition and resuspension of aerosol particles - a new look at some old problems, pp. 1-40, U.S. DOE Tech. Info. Center, Oak Ridge, TN, USA, 1976.

Slinn, W. G. N.: Predictions for particle deposition to vegetative canopies, Atmos. Environ., 16, 1785-1794, 1982.

Smith, M. and Harrison, N.: The sea spray generation function, J. Aerosol Sci., 29, 189-190, 1998.

Stokes, R. H. and Robinson, R. A.: Interactions in aqueous nonelectolyte solutions. I. Solute-solvent equilibria, J. Phys. Chem., 70, 2126-2130, 1966.

Takemura, T., Okamoto, H., Maruyama, Y., Numaguti, A., Higurashi, A., and Nakajima, T.: Tropospheric global threedimensional simulation of aerosol optical thickness distribution of various origins, J. Geophys. Res., 105, 17 853-17 873, 2000.

Tang, I. N.: Thermodynamic and optical properties of mixedsalt aerosols of atmospheric importance, J. Geophys. Res., 102, 
1883-1893, 1997.

Tanré, D., Kaufman, Y. J., Herman, M., and Mattoo, S.: Remote sensing of aerosol properties over oceans using the MODIS/EOS spectral radiances, J. Geophys. Res., 102, 16971-16988, 1997.

Tegen, I. and Lacis, A. A.: Modelling the particle size distribution and its influence on the radiative properties of mineral dust aerosol, J. Geophys. Res., 101, 19237-19244, 1997.

Tegen, I., Hollrig, P., Chin, M., Fung, I., Jacob, D., and Penner, J.: Contribution of different aerosol species to the global aerosol extinction optical thickness: Estimates from model results, J. Geophys. Res., 102, 23 895-23 915, 1997.

Tegen, I., Harrison, S. P., Kohfeld, K., Prentice, I. C., Coe, M., and Heimann, M.: Impact of vegetation and preferential source areas on global dust aerosol: Results from a model study, J. Geophys. Res., 107, 4576-4597, 2002.

Tiedtke, M.: A comprehensive mass flux scheme for cumulus parameterization in large scale models, Mon. Wea. Rev., 117, 1779-1800, 1989.

Timmreck, C. and Schulz, M.: Significant dust simulation differences in nudged and climatological operation mode of the AGCM ECHAM, J. Geophys. Res., 109, D13 202, doi:10.1029/2003JD004 381, 2004.

Tompkins, A.: A prognostic parameterization for the subgrid-scale variability of water vapor and clouds in large-scale models and its use to diagnose cloud cover, J. Atmos. Sci., 59, 1917-1942, 2002.

Toon, O. B. and Ackerman, T. P.: Algorithms for the calculation of scattering by stratified spheres, Appl. Opt., 20, 3657-3660, 1981.

Torres, O., Bhartia, P., Herman, J., Sinyuk, A., and Holben, B.: A long term record of aerosol optical thickness from TOMS observations and comparison to AERONET measurements, J. Atmos. Sci., 59, 398-413, 2002.

Tsigaridis, K. and Kanakidou, M.: Global modelling of secondary organic aerosol in the troposphere: a sensitivity analysis, Atmos. Chem. Phys., 3, 1849-1869, 2003.

Twomey, S.: Pollution and the planetary albedo, Atmos. Environ., 8, 1251-1256, 1974.

Twomey, S.: The Influence of Pollution on the Shortwave Albedo of Clouds, J. Atmos. Sci., 34, 1149-1152, 1977.

Unsworth, J., Wauchope, R., Klein, A., Dorn, E., Zeeh, B., Yeh, S., Akerblom, M., Racke, K., and Rubin, B.: Significance of long-range transport of pesticides in the atmosphere, Pure Appl. Chem., 71, 1359-1383, 1999.

van der Werf, G. R., Randerson, J. T., Collatz, G. J., and Giglio, L.: Carbon emissions from fires in tropical and subtropical ecosystems, Global Change Biology, 9, 547-562, 2003.

van Pul, W., de Leeuw, F., van Jaarsveld, J., van der Gaag, M., and Sliggers, C.: The potential for long-range transboundary atmospheric transport, Chemosphere, 37, 113-141, 1998.

Vehkamäki, H., Kulmala, M., Napari, I., Lehtinen, K. E. J., Timmreck, C., Noppel, M., and Laaksonen, A.: An improved parameterization for sulfuric acid water nucleation rates for tropospheric and stratospheric conditions, J. Geophys. Res., 107, 4622-4632, 2002.

Vignati, E., Wilson, J., and Stier, P.: M7: a size resolved aerosol mixture module for the use in global aerosol models, J. Geophys. Res., 109, D22 202, doi:10.1029/2003JD004 485, 2004.

Vink, S. and Measures, C.: The role of dust deposition in determining surface water distributions of $\mathrm{Al}$ and $\mathrm{Fe}$ in the South West Atlantic, Deep See Res., 48, 2782-2809, 2001.

Wilson, J., Cuvelier, C., and Raes, F.: A modelling study of global mixed aerosol fields, J. Geophys. Res., 106, 34 081-34 108, 2001.

Zadanovskii, A. B.: New methods for calculating solubilities of electrolytes in multicomponent systems, Zhur. Fiz. Kim., 22, 1475-1485, 1948. 